\title{
CRECIDAS E INUNDACIONES DURANTE EL INVIERNO 2000-2001 EN LA CIUDAD DE VALLADOLID Y SU ENTORNO
}

\author{
Ma Teresa Ortega Villazán \\ Carlos Morales Rodríguez \\ Departamento de Geografía \\ Universidad de Valladolid
}

\section{Introducción}

La crecida que experimentó el río Pisuerga a su paso por Valladolid el 6 de marzo de 2001 ha sido una de las peores sufridas en los últimos 40 años. Fue la culminación de un proceso de reiteradas subidas de caudal y de inundaciones desarrolladas a lo largo del invierno 2000-2001. Sin embargo, no constituyó un caso aislado dentro de la región pues muchos de los ríos que la recorren, de muy diferente caudal y potencia erosiva, se vieron asimismo crecidos y desbordados en esas fechas.

Tampoco se ha tratado de un episodio de inundación impredecible, como algunos medios de comunicación y los organismos responsables del control de la Cuenca del Duero han querido hacer ver ${ }^{1}$. Con la evolución que venía teniendo la dinámica atmosférica desde unos meses atrás, y del consiguiente comportamiento del Pisuerga y de otros afluentes del Duero no era en absoluto difícil que este acontecimiento se produjera. El otoño-invierno 2000-2001 estaba siendo un período muy húmedo por las elevadas cuantías pluviométricos registradas, lo que ya venía provocando varios episodios de aguas altas con resultado de inundación. En muchos de los ríos de la Cuenca del Duero la inundación de primeros de marzo ya era la cuarta o quinta padecida. En Valladolid no siempre tuvieron iguales efectos estas subidas pese a que los caudales se mantuvieron altos durante todo el período.

Había, por tanto, motivos más que suficientes para estar sobre aviso, puesto que bastantes colectores de la región llevaban más agua que de costumbre y los embalses estaban al máximo de sus posibilidades, con capacidades de resguardo ínfimas. Con este panorama un incremento de caudal podía ser suficiente para que los ríos ocuparan sus lechos menores y alcanzaran los mayores donde les fuera posible, como de hecho sucedió. En cualquier

1 Desafortunadas fueron las declaraciones hechas por el presidente de la Confederación Hidrográfica del Duero a los medios de comunicación: «No era posible avisar antes de una crecida cuya magnitud era extraordinaria y no se esperaba» (diarios El Norte de Castilla y ABC Valladolid del día 7 de marzo de 2001).

Fecha de recepción: 28 de junio de 2001. Fecha de aceptación: 15 de noviembre de 2001 . 
caso, la que será histórica inundación del 6 de marzo, junto a las otras padecidas este invierno, han sido la consecuencia lógica del comportamiento seguido por la dinámica de la atmósfera en los últimos meses, unido a las características físicas de las cuencas hidrográficas afectadas.

\section{A propósito de las inundaciones en Valladolid}

Valladolid es una ciudad con tradición en cuanto acontecimientos de este tipo se refiere. De hecho cuando las inundaciones acontecen, cobra más sentido que nunca un posible origen de nombre: «vallis toletum», valle de aguas ${ }^{2}$. Y es que en sus primeros asentamientos primaron, entre otros, factores de orden natural, como era la confluencia que sobre este territorio se producía entre los ríos Pisuerga y Esgueva. Esta circunstancia ha favorecido que, desde antiguo, la ciudad haya vivido repetidas inundaciones. Unas veces eran del Pisuerga, otras de la Esgueva, o bien de ambos ríos a la vez ${ }^{3}$. Algunas de las más significativas de los últimos 500 años, catalogadas como inundaciones históricas, aparecen recogidas en el Cuadro I.

Como es lógico la de este año (6 de marzo de 2001) ha sido rápidamente calificada por los medios de comunicación como «otra inundación histórica», puesto que de hecho así ha sido. Por lo tanto, no tiene nada de extemporánea ni de extraña. Es una de las muchas que ha experimentado este río y de las que le quedan por pasar, un fenómeno natural y normal que cada cierto tiempo se manifiesta con diferente intensidad y que siempre desempeña un importante papel regulador dentro del equilibrio del sistema ecológico. Se trata de un episodio más de su comportamiento, aunque la hayan calificado como «la avenida de los 500 años» y pese a que la realidad demuestre que no es necesario dejar pasar medio milenio para que estos acontecimientos se produzcan o incluso se repitan ${ }^{4}$.

Es un hecho claro que las crecidas e inundaciones que experimentan los ríos en Castilla y León tienen su importancia por la relativa frecuencia con que se producen. Según un informe realizado por la Comisión Nacional de Protección Civil (1988), en los 500 años que median entre 1483 y 1985 se han detectado 278 inundaciones históricas sólo en la Cuenca del Duero, con un período de recurrencia cada dos años. Esto representa el 11,4\% de total de las producidas en todo el país en ese mismo intervalo. Esta región únicamente se ve superada por las ocurridas en la Cuenca del Ebro, con 502 episodios, y en la del Guadalquivir con 474 casos $^{5}$.

No obstante, éstas posiblemente fueran más y no hayan quedado recogidas en las crónicas de la época. Las crecidas de antaño, si no producían daños, carecían de interés. No se tenían por inundaciones. Este panorama es bien distinto en la actualidad. Se da la aparente paradoja de que pese a estar más controlados los cauces parece existir un mayor número de

2 Ma Antonia Fernández. Cuadernos vallisoletanos. Tomo 1

3 La Esgueva, como es denominada en Valladolid, tenía en origen tres ramales en su desembocadura al Pisuerga. Entre ellos se asentó la primitiva ciudad, lo que la hacía muy peligrosa ante cualquier crecida. Muchos fueron los daños que originó hasta la desecación de dos de sus ramales y actual canalización (ver García Fernández, J. (2000): Valladolid. De la ciudad a la aglomeración. Ariel. pág. 33 y ss.).

4 Este argumento — el «famoso» de la Q500_, es sobre el que se ha basado la Confederación Hidrográfica del Duero (CHD) para salir del paso de las numerosas críticas, que con cierta razón, sobre este organismo se han formulado.

5 Comisión Nacional de Protección Civil (1988). Las inundaciones en la España Peninsular. Síntesis. MOPU. 


\section{Cuadro I}

CRECIDAS E INUNDACIONES HISTÓRICAS QUE HAN AFECTADO A VALLADOLID EN LOS ÚLTIMOS 500 AÑOS

\begin{tabular}{|c|c|}
\hline SIGLO XVI & $\begin{array}{l}\text { - } 5 \text { de mayo de } 1511 \text { (Pisuerga en Valladolid) } \\
\text { - } 26 \text { de enero de } 1582 \text { (Pisuerga y Arlanzón en Burgos) } \\
\text { - } 24 \text { de mayo de } 1582 \text { (Pisuerga y Esgueva en Valladolid); } \\
\text { - } 14 \text { a } 16 \text { de enero de } 1597 \text { (Esla, Pisuerga, Esgueva, Duero en Zamora). Los dos ríos que atraviesan Valladolid se } \\
\text { llevaron tras de sí } 30 \text { casas del barrio de San Juan. }\end{array}$ \\
\hline SIGLO XVII & $\begin{array}{l}\text { - } 5 \text { de febrero de } 1603 \text { (Pisuerga y Esgueva en Valladolid) } \\
\text { - } 26 \text { mayo de } 1605 \text { (inundación en Valladolid); } \\
\text { - } \text { Octubre de } 1614 \text { (inundación en Valladolid) } \\
\text { - } 12 \text { de febrero de } 1626 \text { (inundaciones en Toro, Zamora, Valladolid y Soria) } \\
\text { - } 4 \text { de febrero de } 1635 \text { (inundación en Valladolid) } \\
\text { - } 3 \text { y } 4 \text { de febrero de } 1636 \text { (Arlanzón en Burgos, Pisuerga y Esgueva en Valladolid, Duero en Zamora). Las aguas del } \\
\text { Pisuerga llegaron a las puertas del Teatro y las de la Esgueva se metieron en el hospital de Orates. Su recuerdo está } \\
\text { impreso en piedra de inscripción en el monasterio de las monjas de Santa Teresa donde reza «Aquí llegó Pisuerga a } \\
4 \text { de febrero de } 1636 . \text { Alabado sea el Santísimo Sacramento». Murieron más de } 150 \text { personas. El cauce del Pisuerga } \\
\text { subió } 12 \text { metros. } \\
\text { - } 26 \text { de diciembre de } 1657 \text { (inundación en Valladolid) } \\
\text { - } 1692 \text { (inundación en Valladolid) }\end{array}$ \\
\hline SIGLO XVIII & $\begin{array}{l}\text { - } 4 \text { de febrero de } 1736 \text { (Pisuerga en Valladolid) } \\
\text { - } \text { otoño de } 1739 \text { (grandes inundaciones en Zamora, Valladolid y Benavente) } \\
\text { - } \text { diciembre de } 1739 \text { (Duero, Tormes y Pisuerga). El Pisuerga saltó por encima del Puente Mayor y la Esgueva alcanzó } \\
\text { el sagrario de la Iglesia de la Cruz. } \\
\text { - } \text { abril y mayo de } 1740 \text { (crecidas); } \\
\text { - } 11 \text { y } 12 \text { de abril de } 1769 \text { (Pisuerga y Tormes en Salamanca) } \\
\text { - } 25 \text { de febrero de } 1788 \text { (inundaciones en Zamora, Salamanca y tremenda en Valladolid); } \\
\text { - } 1789 \text { (Esgueva en Valladolid). En la madrugada de la fiesta de S. Matías, la Esgueva volvió a desbordarse principalmente } \\
\text { por falta de limpieza de su cauce y por las barrabasadas que hacían los arrendatarios del molino de papel, que abrían } \\
\text { y cerraban las compuertas a su antojo para llevar agua a su molino. }\end{array}$ \\
\hline SIGLO XIX & $\begin{array}{l}\text { - enero de } 1821 \text { (Pisuerga) } \\
\text { - febrero de } 1823 \text { (Pisuerga y Esla) } \\
\text { - } \text { abril de } 1829 \text { (Pisuerga y Duero) } \\
\text { - enero de } 1831 \\
-\quad \text { de marzo a mayo de } 1831 \text { (varias crecidas repentinas) } \\
-1842 \text { (inundación en Valladolid) } \\
-12 \text { de febrero de } 1843 \text { (Pisuerga, trágica inundación en Valladolid) } \\
-1847 \text { (Pisuerga) } \\
-1848 \text { (inundaciones en Valladolid y Zamora) } \\
- \text { primavera de } 1853 \text { (varias riadas) } \\
- \text { abril, mayo y junio de } 1892 \text { (varias riadas del Pisuerga) }\end{array}$ \\
\hline SIGLO XX & $\begin{array}{l}\text { - } 9 \text { de julio de } 1904 \text { (inundaciones en la provincia de Valladolid) } \\
\text { - } 1924 \text { (Esgueva en Valladolid) } \\
\text { - } 1935 \text { (Esgueva). La Esgueva volvió a circular por San Juan, los Vadillos y San Andrés llegando hasta la Plaza de Madrid. } \\
\text { - } 1947 \text { y } 1948 \text { (Pisuerga) } \\
\text { - finales de marzo de } 1956 \text { (generalizadas con cuantiosos daños en la agricultura y vías de comunicación) } \\
\text { - } 29 \text { febrero de } 1959 \text { el Pisuerga llevó } 1092 \mathrm{~m}^{3} / \mathrm{seg} \text {. } \\
\text { - } \text { El } 19 \text { de febrero de } 1960 \text { llevó } 1627 \mathrm{~m}^{3} / \mathrm{seg} \text {. } \\
\text { - } 3 \text { de enero de } 1962 \text {, las aguas del Pisuerga cruzaron el Paseo de Isabel la Católica y llegaron hasta Correos (Plaza de la } \\
\text { Rinconada). La Esgueva se reforzó con sacos terreros. El caudal máximo en aquel momento fue de } 2200 \mathrm{~m}^{3} / \mathrm{seg,} \mathrm{no} \mathrm{obstante,} \\
\text { el cauce del Pisuerga no estaba como hoy día y parte de la ciudad carecía de la red de tuberías y colectores apropiadas } \\
\text { - } 11 \text { de febrero de } 1985 \text { (inundaciones en Burgos, León, Salamanca, Valladolid y Zamora) } \\
\text { - } 8 \text { enero de } 1996 \text { el Pisuerga creció a } 1200 \mathrm{~m}^{3} / \mathrm{seg} \\
\text { - } 20 \text { diciembre de } 1997 \text { el Pisuerga subió a } 1334 \mathrm{~m}^{3} / \mathrm{seg} \\
\text { - } 9 \text { de diciembre de } 2000 \text { el Pisuerga lleva un caudal de } 1234 \mathrm{~m}^{3} / \mathrm{seg}\end{array}$ \\
\hline SIGLO XXI & $\begin{array}{l}\text { - } 13 \text { de enero de } 2001 \text { el Pisuerga alcanza los } 1400 \mathrm{~m}^{3} / \mathrm{seg} \\
\text { - } 9 \text { de febrero de } 2001 \text { el Pisuerga lleva } 1301 \mathrm{~m}^{3} / \mathrm{seg} \\
\text { - } 6 \text { de marzo de } 2001 \text { alcanza los } 2682 \mathrm{~m}^{3} / \mathrm{seg} \text { a las } 16 \text { horas. Siete metros de profundidad y diez veces más del caudal } \\
\text { habitual. }\end{array}$ \\
\hline
\end{tabular}

Fuentes: Font Tullot, I. (1988) Historia del clima de España. Cambios climáticos y sus causas.

Efemérides Meteorológicas. INM. El Norte de Castilla (periódico).

Investigaciones Geográficas, no 27 (2002) 
ellas. Pero esto no es necesariamente así sino que al haber más y mejores medios para su estudio y control, se registran en mayor abundancia. Además, la mayor ocupación del territorio y la diversificación de usos en las vegas, ha aumentado el riesgo de las crecidas y sus efectos, que otrora tenían un impacto más reducido en la sociedad. No es extraño por tanto, que una crecida pase a generar más daños que beneficios. Ha aumentado así el riesgo, y no la probabilidad de ocurrencia.

De cualquier modo, las inundaciones en esta región tienen una frecuencia relativamente grande. De los múltiples colectores que la recorren, uno de los que más contribuyen a incrementar esta cifra es sin duda el Pisuerga, muchas veces a coevo con la Esgueva, cuyas inundaciones -75 episodios-, representan el $27 \%$ de las ocurridas en el período anteriormente señalado (1483-1985).

Más tarde o más temprano acontecen sucesos extremos que echan por tierra costumbres y confianzas. Y esto es lo normal. Esos valores, aunque expresivos de la realidad, son orientativos. Como es lógico, no todos los años llueve y nieva lo mismo, ni con igual intensidad ni sobre los mismos lugares, con lo que tampoco todos los años las inundaciones afectarán a los mismos sitios ni traerán iguales consecuencias. Ello depende del papel primordial que ejerce la dinámica de la atmósfera.

\section{Las inundaciones y la dinámica atmosférica}

En un intento de clasificar los tipos de inundaciones que afectan a Castilla y León y por ende a Valladolid, desde el punto de vista de las causas sinópticas que las motivan, puede diferenciarse por un lado las inundaciones del período central del invierno, desarrolladas de diciembre a febrero, muchas veces prolongadas a marzo y, por otro lado, las inundaciones de verano, producidas de junio a septiembre.

Las primeras se deben normalmente a circulaciones de alto índice zonal o bien a circulaciones algo más onduladas, donde el paso casi continuo de borrascas desde el oeste de la Península Ibérica apenas da tregua al desarrollo de situaciones inestables. Otras veces, a estas situaciones de lluvias duraderas se unen deshielos prematuros, representando incluso episodios de mayor peligrosidad. Tanto en uno como en otro caso, suelen denominarse $l l u$ vias de temporal.

A diferencia, las que se producen en verano se deben a fenómenos tormentosos muy fuertes que generan chaparradas de alta intensidad y escasa duración, que fomentan las denominadas lluvias de precipitación in situ, inundaciones relámpago o de tipo flash. Aunque las cantidades que arrojan no son capaces de originar crecidas en ríos de primer y segundo orden, sí pueden motivar avenidas de tipo torrencial en las desembocaduras y confluencias de pequeños arroyos hacia colectores más importantes. Así sucede en muchos de los que nacen en las estribaciones de los páramos, caso de los ríos Bajoz y Hornija que descienden de los Montes Torozos hacia el SO, el $\mathrm{A}^{\circ}$ Santa María que lo hace del páramo de Portillo o el $\mathrm{A}^{\mathrm{o}}$ Valimón del páramo de Montemayor. Asimismo, estas tormentas producen frecuentes encharcamientos tanto en amplias zonas arcillosas y de poca pendiente de la provincia (municipios de Villalón de Campos, Rueda, La Seca y Medina del Campo), como en las áreas urbanas ante la incapacidad momentánea de las redes de saneamiento para la evacuación.

Centrándonos en las primeras, dado que las desarrolladas este invierno 2000-01 pertenecen a la modalidad de abundantes lluvias y/o deshielo prematuro, podemos establecer las siguientes consideraciones. 


\subsection{Las inundaciones por abundantes precipitaciones durante el otoño-invierno. El caso} de las inundaciones de diciembre de 2000 y enero de 2001

Hay años en que las inundaciones que han afectado a la ciudad de Valladolid se han debido fundamentalmente a las abundantes lluvias acaecidas tras un largo período de tiempo. Normalmente se tratan de inviernos en los que ha habido una sucesión muy continuada de frentes asociados a circulaciones zonales, a vaguadas de aire Polar marino ( $\mathrm{Pm})$ localizadas al oeste de la Península, o bien, centradas en la misma (Fig. 1). Los vientos que
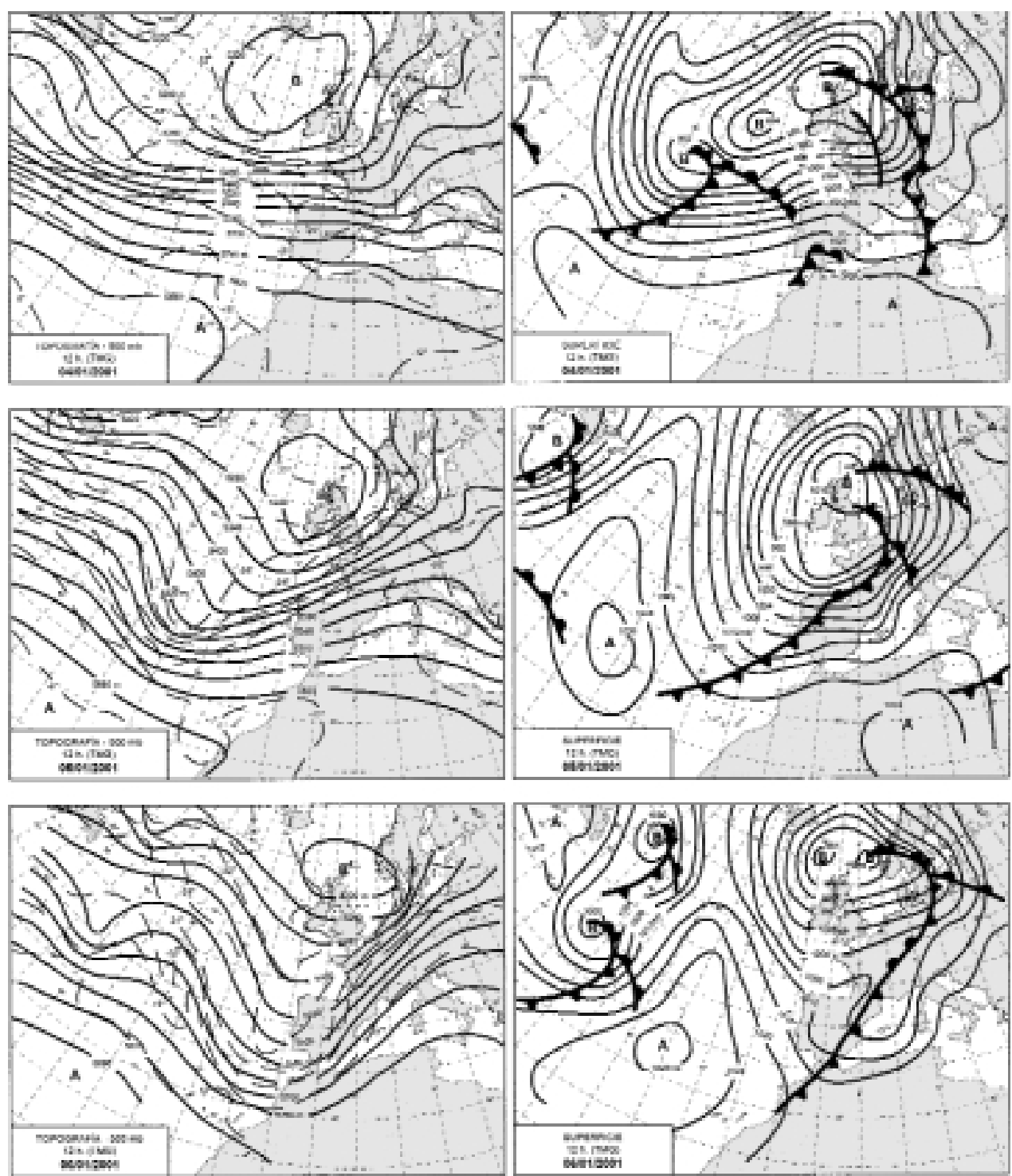

FIGURA 1. Situaciones sinópticas de los días 4, 5 y 6 de enero de 2001.

Investigaciones Geográficas, $n^{\circ} 27$ (2002) 
soplan sobre la región pueden ser, por tanto, del noroeste, oeste o suroeste, y las lluvias bastante regulares y de media o baja intensidad horaria, pudiendo durar todo el día y aún prolongarse durante varias jornadas seguidas. Con estas situaciones las heladas tienen su pausa.

En los años en que se suceden estos tipos de tiempo, manteniéndose durante dos o tres semanas, a veces más, es cuando se producen grandes ejarbes cuya manifestación inmediata son las crecidas de los ríos. De ser inviernos muy lluviosos, lo esperado son las inundaciones, de diferente extensión. Estas pueden ser más o menos generalizadas para la Cuenca del Duero, pero más habitual es que afecten a los ríos que nacen en los sectores occidental y central de la Cordillera Cantábrica (redes del Esla y Pisuerga) y al noroeste de la Cordillera Ibérica (ríos Arlanzón y Arlanza). En cambio, cuando los inviernos no son tan lluviosos, las crecidas son menores y las posibles inundaciones tienen un carácter local.

En los ríos Pisuerga y Esgueva, que son los que atraviesan Valladolid, este tipo de inundaciones han tenido lugar en el 75,4\% de las ocasiones entre diciembre y febrero (período 1959-2001), ampliándose hasta un $95 \%$ si se contabilizan de noviembre a marzo. De igual forma, las padecidas a lo largo del mes de diciembre de 2000 y enero de 2001 en muchos puntos de la región también han respondido fundamentalmente a este hecho, a las abundantes precipitaciones contabilizadas. Y es que el otoño-invierno recientemente pasado ha sido muy lluvioso, en algunos puntos, caso de Valladolid, el más lluvioso de los últimos 40 años. Desde el 1 de septiembre de 2000 al 28 de febrero de 2001, se han registrado en esta ciudad 441,4 mm, cuando su media anual es de 445,6 mm (período 1960-00). Pero veamos como se han producido las precipitaciones.

- Tanto septiembre como febrero han registrado índices por debajo de su media: 27,2 mm de 31,4 mm y 28,9 de 32,0 respectivamente. En cambio, el resto de los meses han tenido índices muy elevados: 52,6 mm en octubre (de 33,6 mm de media), 113,1 $\mathrm{mm}$ en noviembre (de 45,9 $\mathrm{mm}$ ), 95,1 $\mathrm{mm}$ en diciembre (de 40,1 $\mathrm{mm}$ ) y 124,0 $\mathrm{mm}$ en enero (de $42,8 \mathrm{~mm}$ ). A esto habría que unir los $61,8 \mathrm{~mm}$ recogidos la primera semana de marzo, lo que eleva el total a 503,2 $\mathrm{mm}$. Y esto en un lugar del interior de las llanuras. !Lo que no se habrá producido en las montañas más septentrionales!

- Sin embargo este hecho no puede catalogarse como algo excepcional pues no constituye un acontecimiento inusitado. En el anteriormente referido período de observación (41 años) un 31,7\% de los años han registrado otoños-inviernos igualmente húmedos, con un total de precipitación que ronda o supera los $350 \mathrm{~mm}$, si bien es cierto que la máxima cantidad recogida ha correspondido a este último invierno, que sobrepasa en algunas decenas de milímetros la de otros años (Cuadro II).

- La cuantía de este último invierno en general no se ha debido a una especial intensidad de las precipitaciones, aunque haya habido días con altos registros, sino a una regularidad extraordinaria de las lluvias en estos últimos meses ${ }^{6}$. De hecho, desde noviembre a febrero se ha producido la mayor concentración de días de lluvia de los últimos diez años. A modo de ejemplo, los vallisoletanos tuvimos que sacar el paraguas 17 días en noviembre, 21 en diciembre y 19 en enero. Todo un récord.

6 La mayor cantidad caída en Valladolid desde septiembre de 2000 a febrero de 2001 fueron los $26 \mathrm{~mm}$ del día 5 de enero, umbral por debajo de lo que se considera precipitación intensa. Sin embargo, tanto en noviembre, diciembre como enero, en tres de sus días se recogió entre el 40-50\% de la precipitación de cada mes. Hubo pues, cierta concentración de precipitación en algunos de sus días pero nunca con valores muy intensos. 
Cuadro II

RELACIÓN DE OTOÑOS-INVIERNOS LLUVIOSOS EN VALLADOLID Y SU RELACIÓN CON LOS EPISODIOS DE INUNDACIÓN (Período 1960-2001)

\begin{tabular}{|c|c|c|c|c|}
\hline $\begin{array}{l}\text { Otoño- } \\
\text { Invierno } \\
\text { (Años) }\end{array}$ & $\begin{array}{c}\text { Precipitación } \\
\text { Septiembre a Febrero } \\
(\mathbf{m m})\end{array}$ & $\begin{array}{l}\text { Preci } \\
\text { Nov., D } \\
(\mathbf{m m})\end{array}$ & $\begin{array}{l}\text { ción } \\
\text { Enero } \\
\%\end{array}$ & $\begin{array}{l}\text { Inundaciones de los ríos } \\
\text { Pisuerga y/o Esgueva }\end{array}$ \\
\hline $1960-61$ & 395,9 & 175,8 & 44,4 & 20-XII-1960 a 5-I-1961 \\
\hline $1961-62$ & 394,6 & 247,3 & 62,7 & 28-XI-1961 a 5-I-1962; 11-03-62 \\
\hline $1963-64$ & 372,1 & 193,3 & 52,0 & 13 a $18-X I-1963$ \\
\hline $1965-66$ & 426,3 & 214,9 & 50,4 & 20-I-1966 a 21-II-1966 \\
\hline $1970-71$ & 371,3 & 270,3 & 72,8 & - \\
\hline $1976-77$ & 388,1 & 219,8 & 56,6 & 1 a $15-I-1977$ \\
\hline $1977-78$ & 334,9 & 180,9 & 54,0 & 1 a 3-I-1978; 1 y 2-III-1978 \\
\hline $1978-79$ & 373,9 & 240,1 & 64,2 & 29-I-1979; 12-II-1979 \\
\hline $1984-85$ & 352,5 & 232,3 & 65,9 & 11-II-1985 \\
\hline $1989-90$ & 356,6 & 293,6 & 82,3 & - \\
\hline $1995-96$ & 368,5 & 311,8 & 84,6 & 25-XII-1995 a 23-I-1996 \\
\hline $1997-98$ & 422,8 & 350,1 & 82,8 & 6 a 14-XI-1997; 18 a 20-XII-1997 \\
\hline $2000-01$ & 441,4 & 332,2 & 75,3 & 9-XII-2000; 8 a 13-I-2000; 9-II-2001; 6-III-2001 \\
\hline
\end{tabular}

Fuente: Centro Meteorológico Territorial en Castilla y León. Periódico El Norte de Castilla.

- Por otra parte, durante los meses de otoño-invierno son los de noviembre, diciembre y enero los que concentran la mayor parte de la precipitación caída, con porcentajes que oscilan entre un $45 \%$ a un $85 \%$ del total de ese período. Llama la atención que pese a ser el último invierno el más lluvioso, la lluvia acumulada de estos tres meses no es la más elevada de dicho período. En cualquier caso se tratan de meses que la experiencia ha demostrado como muy proclives al desencadenamiento de episodios de inundación (Cuadro II).

Por lo tanto, no es nada descabellado el afirmar que cuando acontecen otoños-inviernos muy lluviosos, con precipitaciones entre los 350-400 $\mathrm{mm}$ - que superan en mucho lo que es habitual-, existe una altísima probabilidad de que se produzcan inundaciones en esta ciudad y su entorno. No tienen porqué producirse siempre, pero sí es la respuesta más normal. Es una realidad que no se debería pasar por alto en cualquier valoración de hipótesis de riesgo de inundación y en las normas de prevención de los organismos rectores de Cuenca.

Pero si éste ha sido un invierno lluvioso, también lo ha sido templado. Consecuencia bastante lógica ante el tipo de circulación atmosférica que ha predominado. La nota dominante ha venido dada por la circulación de carácter zonal con un casi constante pasar de borrascas por el oeste de la Península, y de vaguadas Pm con su zona de salida sobre la misma desatando vientos del suroeste.

Con este dominio de situaciones de inestabilidad templadas apenas ha habido días de helada. Estas se han producido siempre que ha ocurrido alguna situación anticiclónica (escasas en estos meses), vaguadas de aire ártico marino (Am) y circulación zonal inversa (aire polar continental, Pc). Dentro de las capitales de provincia, el primer observatorio en 
registrar una mínima por debajo de $3^{\circ}$ fue Burgos el 3 de octubre de 2000 . También fue esta capital la primera en hacerlo por debajo de los $0^{\circ}$, el día 8 de ese mismo mes. Valladolid en este mes no sólo no registró heladas sino que no tuvo riesgo de ellas (inferiores a $3^{\circ} \mathrm{C}$ ). Hubo que esperar al 10 de noviembre para alcanzar $-0,9^{\circ} \mathrm{C}$.

Otra prueba de esta mayor bonanza del invierno 2000-01 es el hecho de que tampoco las temperaturas mínimas hayan alcanzado valores muy bajos. Mayoritariamente han quedando comprendidas entre los $0^{\circ}$ y $-3^{\circ} \mathrm{C}$. Valladolid y Zamora apenas han conseguido rebasar este último umbral. En ningún momento han adquirido la categoría de valores extremos, pues como mucho han logrado los $-4^{\circ} \mathrm{o}-5^{\circ} \mathrm{C}$ y ello sólo en una ocasión. Se trata del 26 de febrero de 2001, día en el que dentro de las capitales de provincia se alcanzó la mínima más baja de este invierno, registrándola Palencia con $-5,5^{\circ} \mathrm{C}$, seguida de Ávila con $-5,1^{\circ} \mathrm{C}$. La situación atmosférica que la produjo fue una circulación zonal inversa, con vientos del noreste en superficie. En toda la región el frío fue generalizado.

Así pues, el invierno pasado ha tenido un número reducido de días de helada. De octubre a febrero las temperaturas mínimas negativas han oscilado entre un 8,6\% de días en Zamora a un $20,5 \%$ en Palencia (Cuadro III). Son cifras muy alejadas de lo que suele ser habitual otros años. Valga a modo de comparación el número medio de días de helada en las capitales de la región en ese mismo período (octubre a febrero) que oscila entre los 46,9 días de Zamora $(31,1 \%)$ y los 74,2 días de Soria $(49,1 \%)$.

Con estas condiciones de precipitación y temperaturas es como se han producido las numerosas inundaciones de este último invierno en la región. Por lo que concierne a Valladolid, el Pisuerga ha experimentado de diciembre a febrero variaciones importantes en su caudal. Ha visto crecer sus aguas superando en determinados momentos su capacidad máxima estimada en $1200 \mathrm{~m}^{3} / \mathrm{seg}$, cuando el caudal medio para el mes de marzo es de 140 $\mathrm{m}^{3} / \mathrm{seg}$ (y $60,58 \mathrm{~m}^{3} / \mathrm{seg}$ el anual) (Cuadro IV). Unas variaciones y unos umbrales que ya daban cierta idea de cual era su proceder durante este invierno. No obstante, en su recorrido urbano los riesgos de inundación nunca fueron muy elevados al estar su curso bastante cana-

Cuadro III

$N^{\circ}$ DE DÍAS INFERIORES A $3^{\circ} Y 0^{\circ} \mathrm{C}$ DE OCTUBRE DE 2000 A FEBRERO DE 2001 Y VALOR DE LA MEDIA PARA ESE PERÍODO

\begin{tabular}{|c|c|c|c|c|c|c|c|c|c|c|c|c|c|}
\hline \multirow[b]{2}{*}{ Observatorios } & \multicolumn{2}{|c|}{ Octubre } & \multicolumn{2}{|c|}{ Noviembre } & \multicolumn{2}{|c|}{ Diciembre } & \multicolumn{2}{|c|}{ Enero } & \multicolumn{2}{|c|}{ Febrero } & \multicolumn{2}{|c|}{ Total } & \multirow{2}{*}{$\begin{array}{c}\text { Media } \\
<0^{\circ}\end{array}$} \\
\hline & $<3^{\circ}$ & $<0^{\circ}$ & $<3^{\circ}$ & $<0^{\circ}$ & $<3^{\circ}$ & $<0^{\circ}$ & $<3^{\circ}$ & $<0^{\circ}$ & $<3^{\circ}$ & $<0^{\circ}$ & $<3^{\circ}$ & $<0^{\circ}$ & \\
\hline Ávila & 7 & - & 16 & 5 & 17 & 3 & 20 & 4 & 23 & 9 & 83 & 21 & 62,7 \\
\hline Burgos & 5 & 1 & 14 & 4 & 7 & 3 & 17 & 4 & 20 & 12 & 63 & 24 & 51,4 \\
\hline León & 4 & - & 15 & 4 & 14 & 5 & 19 & 8 & 22 & 12 & 74 & 29 & 63,1 \\
\hline Palencia & 3 & - & 16 & 8 & 13 & 4 & 21 & 9 & 22 & 10 & 75 & 31 & 50,5 \\
\hline Salamanca & 5 & - & 14 & 9 & 8 & 2 & 14 & 4 & 19 & 12 & 60 & 27 & 56,3 \\
\hline Segovia & 2 & - & 12 & 3 & 7 & 3 & 14 & 2 & 15 & 7 & 50 & 15 & 51,6 \\
\hline Soria & 3 & - & 17 & 5 & 13 & 5 & 21 & 5 & 21 & 12 & 75 & 27 & 74,2 \\
\hline Valladolid & - & - & 11 & 5 & 6 & 2 & 13 & 3 & 17 & 8 & 49 & 18 & 52,8 \\
\hline Zamora & 1 & - & 9 & 3 & 3 & 2 & 11 & 1 & 16 & 7 & 40 & 13 & 46,9 \\
\hline
\end{tabular}

Fuente: Boletines Meteorológicos Diarios. INM. 
lizado. Todo lo más se anegaban los paseos fluviales, las casetas del barquero o se reducía la extensión de la playa de las Moreras. No puede decirse lo mismo cuando circulaba amplio a lo largo de su vega. Hasta cinco inundaciones habían experimentado algunos pueblos próximos a su cauce en lo que iba de invierno, afectando a amplias zonas de cultivo.

De cualquier modo las precipitaciones que se producen en estos años tan lluviosos hay que considerarlas a escala regional, en el conjunto de toda la cuenca hidrográfica afectada. No en la localidad concreta, ni tan siquiera en las llanuras del interior a las que pertenece, sino en toda la cuenca vertiente del colector que la origina, el Pisuerga en este caso, arrancando desde su cabecera en zonas de montaña. Pues es allí donde se van a producir con mayor intensidad las lluvias y nevadas que más tarde terminarán alimentando a los ríos que de ellas parten (Cuadro V).

$\mathrm{Y}$ es que los ríos en su descenso van adicionando caudales. Corriente abajo las aguas son cada vez más altas, razón que justifica que el carácter más dramático de las inundaciones se produzca en los tramos bajos del colector. Es un hecho claro cuando el Pisuerga cruza Valladolid, después de haber recibido las aguas de otros importantes afluentes como el Rivera, Valdavia, Carrión, Odra, Arlanza y Esgueva. O igualmente frecuente en la

Cuadro IV

VARIACIONES DEL CAUDAL DEL PISUERGA EN VALLADOLID

EN EL INVIERNO 2000-2001 (medidas a las 16 horas)

\begin{tabular}{|c|c|}
\hline Fecha & Caudal \\
\hline 3 - diciembre - 2000 & $600 \mathrm{~m}^{3} / \mathrm{seg}$ \\
9 - diciembre - 2000 & $1234 \mathrm{~m}^{3} / \mathrm{seg}$ \\
8 - enero - 2001 & $1327 \mathrm{~m}^{3} / \mathrm{seg}$ \\
13 - enero - 2001 & $1400 \mathrm{~m}^{3} / \mathrm{seg}$ \\
9 - febrero - 2001 & $1301 \mathrm{~m}^{3} / \mathrm{seg}$ \\
5 - marzo - 2001 & $1429 \mathrm{~m}^{3} / \mathrm{seg}$ \\
6 - marzo - 2001 & $2682 \mathrm{~m}^{3} / \mathrm{seg}$ \\
\hline
\end{tabular}

Fuente: Confederación Hidrográfica del Duero.

Cuadro $\mathrm{V}$

PRECIPITACIÓN REGISTRADA DE OCTUBRE DE 2000 A FEBRERO DE 2001 EN LA CUENCA DEL PISUERGA Y VALOR MEDIO ANUAL ( $\mathrm{mm})$

\begin{tabular}{|l|c|c|}
\hline Observatorio & Precipitación período & Precipitación media \\
\hline Cervera de Pisuerga & $1.274,5$ & 965,3 \\
Aguilar de Campoó & 701,4 & 628,1 \\
Alar del Rey & 538,4 & 634,1 \\
Herrera de Pisuerga & 567,4 & 542,5 \\
Melgar de Fernamental & 431,2 & 484,8 \\
Dueñas & 345,3 & 422,8 \\
Valladolid & 441,4 & 445,6 \\
\hline
\end{tabular}

Fuente: Centro Meteorológico Territorial en Castilla y León. 
comarca de Benavente-Los Valles (Zamora), donde tiene lugar la confluencia entre cuatro arroyos y cinco ríos importantes (confluencia del Ería al Órbigo y de éste al Esla, y las confluencias directas del Cea y Tera sobre el Esla), lo que le hace ser hoy uno de los principales puntos conflictivos — por no decir el que más— de la región.

Aquellos inviernos que han sido lluviosos y por ende más templados, han motivado gran parte de las inundaciones históricas por desbordamiento del río Pisuerga. Estas inundaciones están controladas en gran parte por los parámetros de su propia cuenca, y actualmente muy minimizadas por el efecto laminador de los embalses de cabecera. No ocurre así en sus afluentes que aún no están regulados, caso del Esgueva, mitad burgalés mitad pucelano, o del Arlanza burgalés, entre otros. En general, aunque la probabilidad de ocurrencia de estas inundaciones es alta (en algunos ríos de frecuencia casi anual), son fácilmente predecibles, con lo que su incidencia sobre la sociedad siempre es menor.

Pero no todas las inundaciones responden a este mecanismo, es decir, el de las abundantes precipitaciones por el paso continuado de borrascas en circulación zonal. Otras veces estas lluvias actúan como disparador de un proceso ya engendrado, el de una innivación previa en áreas de montaña.

\subsection{Las inundaciones por procesos de deshielo. El caso de la inundación del 6 de marzo de 2001}

La situación vivida en los primeros días de marzo del presente año se ha debido precisamente a lo anteriormente referido, es decir, a fenómenos de deshielo muy rápidos en conjunción con unas lluvias muy continuadas. Sucesos de este tipo presentan mayor peligrosidad en algunos de los afluentes de primer orden del Duero, sobre todo en los de su margen derecha, nacidos en distintos sectores de la Cordillera Cantábrica, con cierta innivación en sus cabeceras y abundantes caudales (Esla, Órbigo, Carrión, Pisuerga...).

Aunque las inundaciones de este tipo son más factibles durante la primavera, sobre todo si después de un período de grandes nevadas se establecen situaciones anticiclónicas que propician ascensos térmicos, en este caso su origen hay que buscarlo en el paso de situaciones de inestabilidad bastante templadas.

Hay años en que determinadas situaciones de la dinámica atmosférica permiten que las cumbres de las montañas castellanas se cubran de blanco proporcionando una de las imágenes más características del paisaje castellano. Con mayor frecuencia le ocurre a la Cordillera Cantábrica, y a partir de altitudes no muy elevadas. Son sus responsables las vaguadas Am profundas, las circulaciones zonales inversas que traen aire Pc, y las vaguadas Pm de penetración noroccidental también profundas. De acuerdo con sus frecuencias, desarrollo latitudinal e intensidad, el período de innivación puede ser más o menos importante. Si tras ellas se suceden situaciones atmosféricas frías, la nieve se mantiene en las montañas a la espera de una fusión progresiva y lenta a lo largo del período primaveral, pero de llegar dinámicas más templadas o cálidas de la mano de circulaciones zonales del oeste, la nieve se vuelve efímera.

La caída de lluvia templada produce de forma rápida la fusión del manto nivoso, con las consecuencias que esto trae en el incremento del caudal de los ríos. Es entonces cuando éstos crecen con celeridad, sobre todo si el agua que circula por el suelo se encuentra con unos terrenos saturados de posibles lluvias anteriores, como ha sucedido este invierno pasado. Las escorrentías por las vertientes entonces se vuelven máximas, los arroyos se convierten en torrenteras y cuando circulan por terrenos más llanos sobrepasan los límites 
de sus cauces ocupando los lechos menores, o incluso los mayores aguas más abajo a medida que se van sumando los aportes de otros colectores.

Este proceso ha ocurrido en los primeros días de marzo en la cuenca del Pisuerga, siendo muchos los terrenos en ella inundados, aunque si bien uno de los puntos donde tuvo mayor espectacularidad fue al atravesar la ciudad de Valladolid. Y ello no tanto por la magnitud de la inundación, que en muchos tramos no pasó de leves desbordamientos, como por el hecho de ocurrir en un sector del río canalizado y de afectar a un buen número de personas y bienes no alertadas con suficiente antelación.

Desde el punto de vista de la dinámica atmosférica la situación que se vivió puede resumirse de la siguiente manera. Hay que partir de un otoño-invierno muy lluvioso, como ya hemos especificado, que a finales de febrero había dejado en Valladolid 441,4 mm (Cuadro V). Los campos de cultivo en muchos lugares de la provincia venían arrastrando un fuerte grado de encharcamiento, que incluso había obligado a retrasar en muchos puntos la siembra de primavera ${ }^{7}$.

Diez días antes de la inundación del 6 de marzo, se habían producido intensas nevadas en gran parte de la Cordillera Cantábrica, sobre todo los días 24 y 25 de febrero, debido al desarrollo de un proceso circulatorio retrógrado de ocupación muy amplia sobre Europa occidental que traía en superficie vientos muy fríos del noreste (Fig. 2). La cota de nieve en la cabecera del Pisuerga bajó hasta los 700-800 m siendo obligado el cierre de puertos y la circulación con cadenas en buena parte de ellos. Las temperaturas bajaron bruscamente. En gran parte de la región se pasó de los $12^{\circ} / 15^{\circ} \mathrm{C}$ de temperatura máxima del día previo a los $5^{\circ} / 8^{\circ} \mathrm{C}$, y de los $2^{\circ} / 4^{\circ} \mathrm{C}$ de las mínimas a los $-3^{\circ} /-5^{\circ} \mathrm{C}$. Se fraguaba el momento más frío del invierno.

A partir del día 26 de febrero y hasta el 28 , se instaló una vaguada profunda con disposición de eje meridiano de gran amplitud y escasa longitud de onda centrada sobre Europa occidental, que permitió la llegada de aire muy frío y el soplo de vientos fuertes a muy fuertes de componente noroeste sobre la Península. Inmediatamente al oeste de la misma una estrecha cuña anticiclónica alcanzó latitudes muy septentrionales, en un ejemplo muy representativo de circulación fuertemente ondulada. Las nevadas en las montañas continuaban (ahora más como chubascos tormentosos muchas veces acompañados de granizo), mientras que sobre las llanuras se volvían algo más parcas. El tiempo continuaba frío. En la topografía de $500 \mathrm{hPa}$ la isoterma de $-32^{\circ} \mathrm{C}$ cruzaba todo el tercio norte peninsular.

Sin embargo a partir del 1 de marzo tuvo lugar un importante cambio de tipo de tiempo. Una circulación fuertemente zonal del oeste se instaló sin dificultad entre los $30^{\circ} / 45^{\circ}$ de latitud, empujando hacia el norte la vaguada de días anteriores fragmentado al tiempo la cuña anticiclónica en una célula de aire más templado y estable que permaneció bloqueante en mitad del Atlántico norte. Esto supuso la entrada en la región de aire mucho más templado que el de días precedentes con la lógica subida de las temperaturas originando inmediatos procesos de fusión en las montañas. Las mínimas dejaron de ser negativas alcanzando en muchos puntos de la región los $6^{\circ} / 9^{\circ} \mathrm{C}$, mientras que las máximas superaban los $13^{\circ} / 15^{\circ} \mathrm{C}$. En la topografía de $500 \mathrm{hPa}$ la Península quedó cruzada por la isoterma de $-20^{\circ} \mathrm{C}$.

7 Según el consejero de Agricultura de la Junta de Castilla y León, un 26\% de la superficie base de la Comunidad a primeros de marzo aún se encontraba a la espera de siembra, lo que representaba $608.000 \mathrm{Ha}$ del total que asciende a 2,3 millones. De este porcentaje hay que descontar un $10 \%$ que quedaría en barbecho. Por comarcas, Tierra de Campos acusa una situación alarmante con tan sólo un 30\% de la labor realizada. Por provincias destacan Valladolid y Palencia con un 50\% y un 42\% de superficie sin sembrar (152.000 y $200.000 \mathrm{Ha}$ respectivamente). Le siguen León (38\%) y Ávila (24\%). En menor medida se encuentran el resto de las provincias con un media de un $12 \%$ 


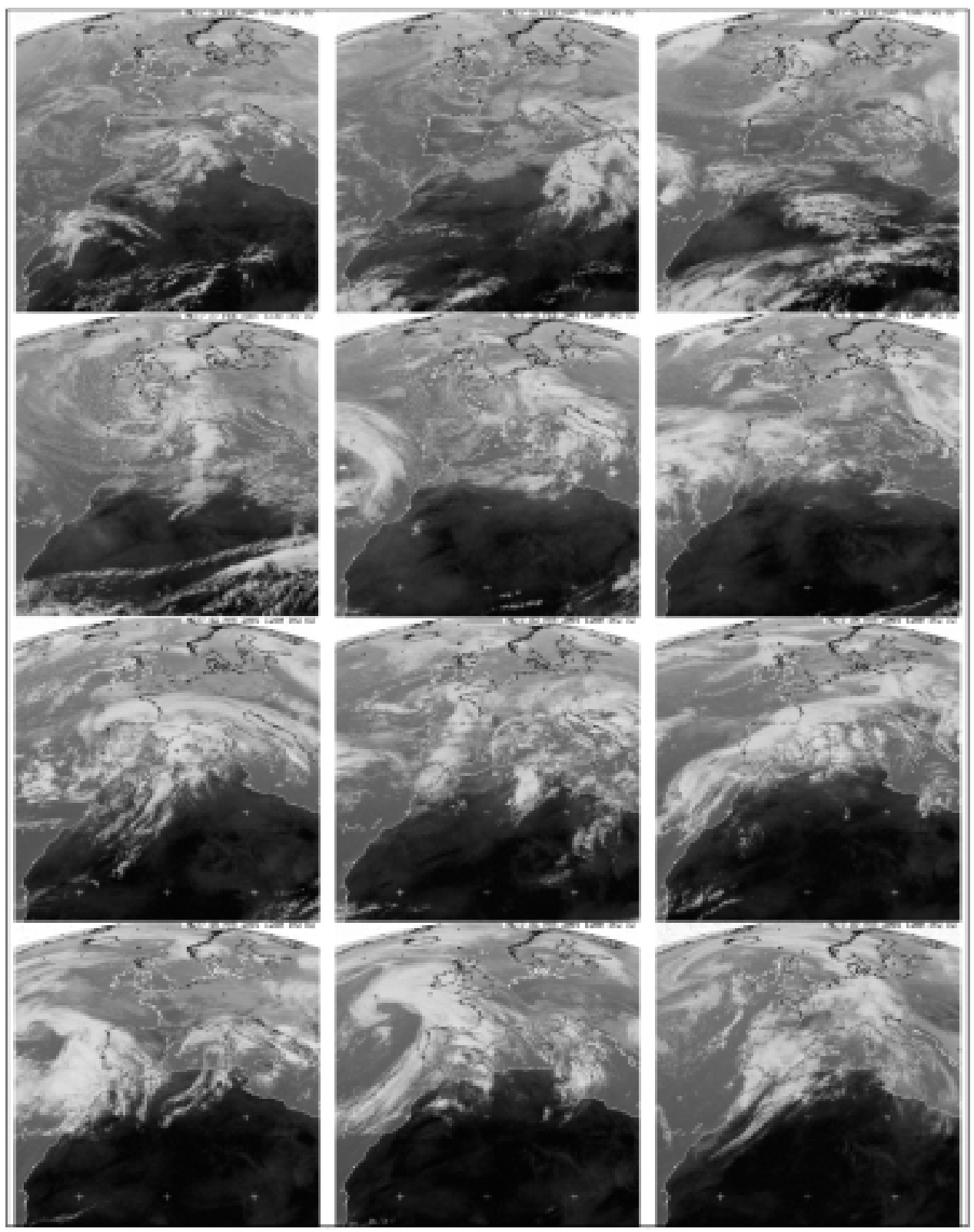

Fuente: Meteosat images. Nottingham University. www.nottingham.ac.uk/meteosat/

FIGURA 2. Evolución de la dinámica atmosférica entre los días 24 de febrero y 7 de marzo de 2001. 


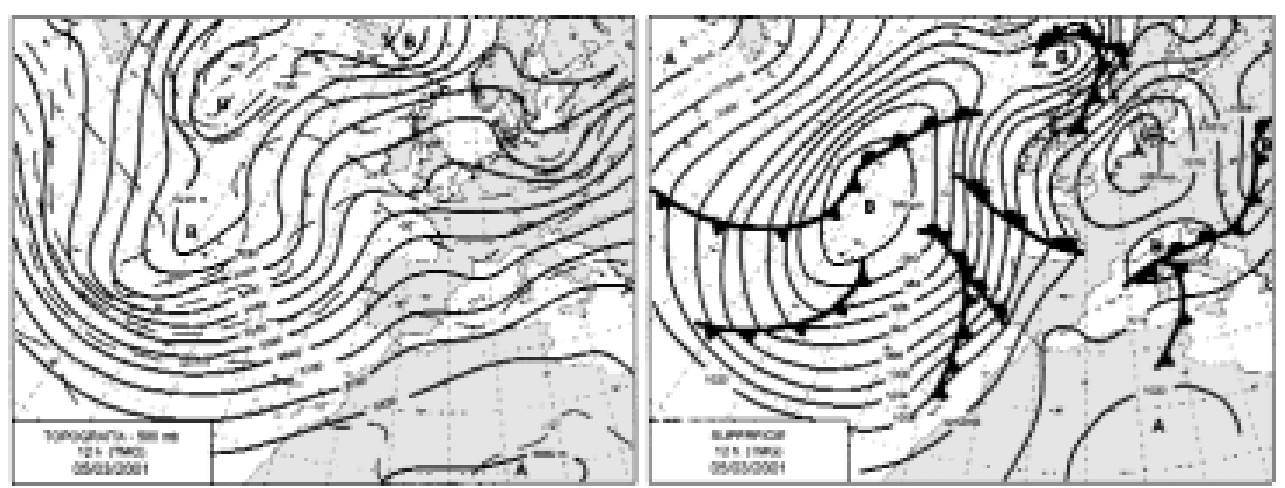

FIGURA 3. Situación sinóptica del día 6 de marzo de 2001.

Durante los cuatro primeros días de marzo el paso de borrascas fue continuo, lo que permitió acumular 51,7 mm en Valladolid, 87 mm en Herrera de Pisuerga, 91,3 mm en Aguilar de Campoó, 175,6 mm en Cervera de Pisuerga y posiblemente más de $200 \mathrm{~mm}$ en cabecera (Cuadro VI).

Cuadro VI

PRECIPITACIONES DIARIAS DE LA PRIMERA SEMANA DE MARZO DE 2001 (mm)

\begin{tabular}{|l|c|c|c|c|c|c|c|}
\hline & $\mathbf{1}$ & $\mathbf{2}$ & $\mathbf{3}$ & $\mathbf{4}$ & $\mathbf{5}$ & $\mathbf{6}$ & $\mathbf{7}$ \\
\hline Cervera de Pisuerga & 41,7 & 49,8 & 48,2 & 35,9 & 25,8 & 1,8 & 2 \\
Aguilar de Campoó & 24,4 & 21,6 & 22,2 & 23,1 & 4,1 & 2,5 & 6 \\
Alar del Rey & 31,3 & 15,8 & 29,3 & 7 & 4,6 & 2,7 & 2,2 \\
Herrera de Pisuerga & 37 & 10 & 25 & 15 & 4,5 & 3,9 & - \\
Melgar de Fernamental & 32,5 & 9 & 17,5 & 15 & 1,5 & 2 & 3,6 \\
Dueñas & 23,1 & 15,9 & 15,3 & 4,8 & 3 & 4,5 & 6,4 \\
Valladolid & 23 & 7,7 & 13 & 8 & 4,1 & 2 & 4 \\
\hline
\end{tabular}

Fuente: Centro Territorial en Castilla y León. Datos diarios.

Los vientos según los días tornaban del oeste o suroeste, pero siempre inmersos en una circulación muy zonalizada. No obstante, a partir del día 5 de marzo comenzó a ondularse una vaguada al oeste de la Península bastante profunda con doble centro sobre el Atlántico (bajas de 964 mb y $968 \mathrm{mb}$ ), que se mantendrían hasta el día 8 (Fig. 3). Su zona de salida permitió la entrada sobre la región de vientos del suroeste, aún más cálidos, y precipitaciones más o menos continuadas. En la topografía de 500 hPa la Península quedó ahora comprendida entre las isotermas de $-12^{\circ}$ y $-16^{\circ} \mathrm{C}$ ). Justamente con este último tipo de tiempo fue cuando sucedió la inundación de Valladolid y su entorno, el 6 de marzo.

La evolución de este proceso de inundación se vivió realmente con angustia. Días previos a su desencadenamiento en otros puntos de la región recorridos por la red del Carrión y del Arlanza se habían producido inundaciones. El 5 de marzo a las $12 \mathrm{~h}$ de la mañana el Pisuerga a su paso por Valladolid llevaba $1229 \mathrm{~m}^{3} / \mathrm{seg}$, alcanzando su punta a las $20,30 \mathrm{~h}$ con $1429 \mathrm{~m}^{3} / \mathrm{seg}$. La situación era de alerta, pero la cifra era similar a la de las crecidas que 
se habían venido experimentando este invierno, lo que llevó probablemente a pensar a la CHD que la situación en este caso seguiría un comportamiento similar.

El sistema de previsión de avenidas que establece la Confederación, considera que el Pisuerga en Valladolid tiene un caudal de alerta si lleva $509 \mathrm{~m}^{3} / \mathrm{seg}$, y alcanza un nivel de peligro si supera los $886,9 \mathrm{~m}^{3} / \mathrm{seg}$. Los caudales estimados para distintos períodos de retorno elevan considerablemente esta cifra (Cuadro VII). Para una posibilidad de ocurrencia de 25 años $\left(Q_{25}\right)$ se estiman $1487 \mathrm{~m}^{3} / \mathrm{seg}$ en Cabezón de Pisuerga, núcleo a $8 \mathrm{~km}$ aguas arriba de esta ciudad y $1616 \mathrm{~m}^{3} / \mathrm{seg}$ en Valladolid. Caudales más extremos se esperan para períodos de 500 años $\left(\mathrm{Q}_{500}\right)$, con $2506 \mathrm{~m}^{3} / \mathrm{seg}$ y $2808 \mathrm{~m}^{3} / \mathrm{seg}$ respectivamente ${ }^{8}$.

Sin embargo, a nuestro entender y a la vista de los caudales que se registraban, los organismos responsables de alertar a la población no actuaron con el suficiente apremio. Es más, ese mismo día desde la Confederación se declaraba refiriéndose a la crecida: «Todo indica que se puede mantener sin que haya peligro por la noche, pero siempre dependemos de que no llueva». O por ejemplo, «el Pisuerga asusta porque es mucho río, pero para que llegue hasta la carretera, como en los años sesenta, tiene que llover todavía mucho»9. Como si fuera la lluvia capaz de caer en aquel momento el principal problema. De hecho, las precipitaciones se habían reducido considerablemente respecto a días previos, manteniéndose esta tendencia en los días siguientes (Cuadro VI).

El período crítico se desarrolló desde la madrugada hasta última hora del martes día 6:

- A las 3 de la madrugada se produjo un repunte causado por los aportes de varios ríos intermedios, «algo que era imprevisible» en palabras del presidente de la Confederación. Aunque mejor dicho, fue algo no previsto por el citado organismo. Las principales causas hay que buscarlas en cómo se realizan las observaciones de vigilancia nocturna en las estaciones foronómicas manuales y en la falta de información de algunas de las automáticas por problemas de funcionamiento, caso del aforo de Cordovilla la Real (Palencia) que dejó de emitir datos ${ }^{10}$.

Cuadro VII

CAUDALES DEL PISUERGA PARA DIFERENTES PERÍODOS DE RETORNO $\left(\mathrm{m}^{3} / \mathrm{seg}\right)$

\begin{tabular}{|l|c|c|c|c|c|c|c|}
\hline & $\mathbf{Q}_{5}$ & $\mathbf{Q}_{10}$ & $\mathbf{Q}_{25}$ & $\mathbf{Q}_{50}$ & $\mathbf{Q}_{100}$ & $\mathbf{Q}_{500}$ & $\mathbf{Q}_{1000}$ \\
\hline Cabezón de Pisuerga & 923 & 1172 & 1487 & 1725 & 1961 & 2506 & 2740 \\
Valladolid & 944 & 1241 & 1616 & 1894 & 2170 & 2808 & 3083 \\
\hline
\end{tabular}

Fuente: Confederación Hidrográfica del Duero. Sec. Aforos. Previsión de Avenidas para el año hidráulico 1999-2000.

8 Los datos de Cabezón corresponden a un valor Gumbel actualizado al año hidrológico 1996-97 según queda recogido en DELEGACIÓN DE GOBIERNO EN CASTILLA Y LEÓN. (1997). Plan provisional de emergencias por inundaciones en la provincia de Valladolid. 93 pp. Cfr. Pág. 15. Los datos de Valladolid, están actualizados a junio de 2001, teniendo en cuenta los últimos caudales máximos instantáneos registrados y han sido facilitados por la Sección de Aforos de la Confederación Hidrográfica del Duero.

9 Según aparece en el periódico $A B C$ Valladolid, del día 5 de marzo de 2001.

10 El Pisuerga, desde su nacimiento en la Fuente del Cobre (Santa $\mathrm{M}^{\mathrm{a}}$ de Redondo en Palencia) hasta su desembocadura en el Duero en Pesqueruela (Simancas), recorre $275 \mathrm{Km}$, ocupando una cuenca de $15.759 \mathrm{Km}^{2}$ y con una aportación media de $2586 \mathrm{Hm}^{3} / \mathrm{año}\left(72,7 \mathrm{~m}^{3} / \mathrm{seg}\right)$. En tan largo recorrido cuenta con once estaciones de aforo, una de carácter histórico (Embalse de Requejada) y diez de la red actual (Cervera de Pisuerga, Salinas de Pisuerga, San Mamés de Zalima, Aguilar de Campoó, Alar del Rey, Herrera de Pisuerga, Cordovilla la Real, Dueñas, Cabezón, Valladolid). En sus afluentes hay que contar con dos aforos sobre el Rivera (Embalse de Cervera y Ruesga), siete sobre el Carrión (Camporredondo, Compuerto, Velilla del Río Carrión, Guardo, Celadilla del Río, Villoldo y Palencia), cuatro sobre el Arlanza (Castrovido, Covarrubias, Quintana del Puente y Peral de Arlanza) y tres sobre el Esgueva (Cabañes de Esgueva, Villanueva de los Infantes y Valladolid). Es una de las subcuencas de la que se tiene más información. 
- A primera hora de la mañana el Pisuerga llevaba en Cabezón el alarmante caudal de $2000 \mathrm{~m}^{3} / \mathrm{seg}$, y ascendía a un ritmo de $30 \mathrm{~cm}$ por hora. Se había superado con creces la cota de riesgo. Su punta máxima en Valladolid se estableció en $2682 \mathrm{~m}^{3} / \mathrm{seg}$ a las 16 horas según los medios de comunicación, si bien la Confederación lo estimó en torno a $2360 \mathrm{~m}^{3} / \mathrm{seg}$ (aforo directo medido). Se sobrepasaron en 4,15 m la altura máxima de las cinco anteriores crecidas habidas en este invierno. El río estuvo a $6,5 \mathrm{~m}$ de altura sobre el nivel medio normal (Fotos 1 y 2).

El río Pisuerga a su paso por Valladolid

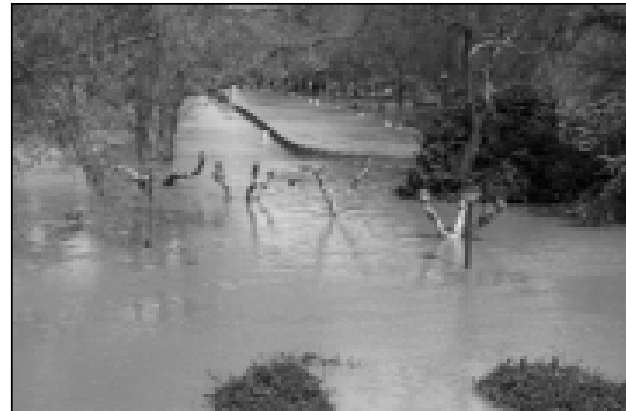

Fото 1. Parque de Las Moreras.

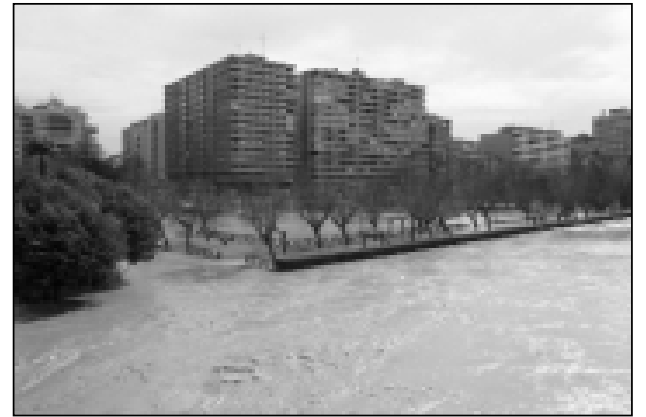

Foto 2. Parque de La Rosaleda.

- En la segunda reunión convocada por el Centro de Coordinación de Emergencias a las 6 de la tarde, el delegado de Gobierno afirmó que «la situación vivida en Valladolid no estaba prevista, en parte porque desde la CHD se confiaba en la capacidad de absorción de los campos de Tierra de Campos, principalmente en las cuencas del Arlanza y Carrión, si bien esto no se había producido porque las lluvias de los últimos días habían saturado las tierras». Sin comentarios.

- A las 7 h. 45' de la tarde las aguas ya habían descendido en Valladolid unos 10 centímetros en el Puente Mayor, con lo que el Pisuerga anunciaba su retirada. Lentamente las aguas fueron volviendo a su cauce. Como era lógico esta crecida con las horas fue propagándose aguas abajo. Así a las 3 de la tarde el caudal del Duero en Tordesillas era de 2500 $\mathrm{m}^{3} / \mathrm{seg}$, de $1763 \mathrm{~m}^{3} / \mathrm{seg}$ en Toro y de $1635 \mathrm{~m}^{3} / \mathrm{seg}$ en el Barrio de Carrascal de la ciudad de Zamora. La punta máxima en esta última ciudad se esperaba para las 10-11 h. de la noche.

A primeras horas del día 7 ya se apreciaba como la tierra poco a poco ganaba terreno al agua, al tiempo que se nos descubría un paisaje sórdido. Maleza, basura, bolsas y un sinfín de suciedad se extendían a lo largo de las riberas, siendo el mejor exponente del rastro dejado por esta fuerte crecida. La alerta ya no se centraba en la capital vallisoletana, sino en las cuencas hidrográficas intermedias de los ríos Carrión y Valdavia (Palencia), en el Esqueva y Arlanza burgalés, y en la comarca zamorana de Benavente-Los Valles, siendo los ríos más implicados el Órbigo, Tera, Valderaduey, Ería y Esla. El día 9 la CHD confirmaba el descenso de todos los ríos de la Cuenca del Duero a excepción del Carrión en la localidad de Villoldo, ya que continuaba el desembalse desde Compuerto que durante la mañana de la jornada anterior - día 8 - era de $125 \mathrm{~m}^{3} / \mathrm{seg}$ y por la tarde se rebajó a los 100 $\mathrm{m}^{3} / \mathrm{seg}$. Mientras en el Pisuerga el caudal continuaba bajando, con menos de $800 \mathrm{~m}^{3} / \mathrm{seg}$ a su paso por Valladolid. 
En los medios de comunicación, en los días siguientes a la inundación era curioso asistir al debate e intercambio de opiniones de cargos políticos, expertos en la materia, afectados... tratando de buscar ante todo un directo responsable de semejante catástrofe. Todo fue apuntando a una cierta falta de coordinación y mal funcionamiento entre las Administraciones y los organismos llamados a intervenir, a saber, el Ayuntamiento, la Diputación, la CHD, la Junta de Castilla y León y Delegación de Gobierno. Sobre todo se trataba de eludir responsabilidades en la denominada fase de pre-emergencia, es decir, aquella en la que por existencia de información se avisa sobre la posibilidad de ocurrencia de sucesos capaces de dar lugar a inundaciones, alertando tanto a las autoridades y servicios implicados como a la población potencialmente afectada ${ }^{11}$. Y es que éste fue quizá el principal problema de esta inundación, la falta de aviso con suficiente antelación a la población localizada en zonas de alto potencial de riesgo. Contra la crecida del Pisuerga y su desbordamiento nada o poco se podía hacer, pero con la alerta a las personas sí que se tenía que haber actuado con mayor premura.

El presidente de la Confederación, principal cabeza de turco que se buscó en este desaguisado, se vio en la obligación de hacer declaraciones al respecto de lo ocurrido, a nuestro parecer desafortunadas. Insistió en que no fue posible prever la magnitud de la crecida: «Nosotros no sabemos hasta donde puede llegar el río. El río tiene un modelo de comportamiento que ahora se ha disparado, por lo que esos datos que hemos obtenido se introducen en el modelo después de una situación extraordinaria. Con los datos estadísticos que se tenían lo que se ha producido es la avenida de los 500 años, es decir, la probabilidad de que en 500 años se produzca una avenida de estas características...... Nosotros en el momento en que vemos que el río va subiendo tampoco sabemos hasta dónde va a llegar. Cuando estás en una situación de alerta tampoco sabes donde va a parar. En comportamientos anteriores no había llegado hasta ese punto». Aunque tampoco le faltó la razón al decir que «Nosotros sólo decimos lo que está sucediendo y ellos (por el Ayuntamiento, entendemos) saben cómo actuar. En el momento en que está subiendo, en la situación de alerta son ellos los que toman las medidas» ${ }^{12}$.

Ante tales palabras surgen algunas preguntas: ¿acaso no se han producido otros episodios similares en magnitud e intensidad en Valladolid o en la región?, ¿han pasado 500 años desde la inundación del 3 de enero de 1962 o de la del 20 de diciembre de 1997?, ¿acaso no se deben contemplar todos los posibles parámetros de la dinámica fluvial y los factores susceptibles de actuar ante un episodio de esta categoría? Son cuestiones para la reflexión.

Lo que sí está claro es que este episodio no fue únicamente el resultado de las lluvias de los últimos días, como algunos medios de comunicación querían hacernos ver: «el temporal que desde el pasado viernes azota a la región», cuando no hubo tal. Esta coyuntura por sí misma no necesariamente tendría que haber generado tan alarmantes subidas en el caudal del río Pisuerga dado que otros muchos años se han producido episodios atmosféricos análogos que no han creado inundaciones tan extremas. La razón fundamental, o mejor dicho, las razones - pues son varias_-, se deben a una serie de hechos que han actuado conjuntamente. Lógicamente de entre ellos destacan los acelerados procesos de deshielo vividos por el paso continuado de borrascas de aire muy templado desde el oeste, que en

11 DIRECCIÓN GENERAL DE PROTECCIÓN CIVIL (1994). Proyecto de Directriz Básica de Planificación de Protección Civil ante el riesgo de inundaciones. 42 pp. Cfr. pág. 10.

12 Según aparece en el periódico $A B C$ Valladolid del día 11 de marzo de 2001. 
apenas cinco días consiguieron incrementar en exceso los caudales de muchos ríos de la región. Pero es no la única causa a tener en cuenta.

\subsection{Los otros factores de la inundación del 6 de marzo de 2001}

Como decíamos, la inundación del 6 de marzo forma parte de un proceso mucho más largo y complejo, ya en parte explicado, donde los fenómenos de deshielo han jugado un papel fundamental, pero también hay que ahondar en otros factores.

- Por un lado, las abundantes y frecuentes precipitaciones que se venían padeciendo desde el otoño pasado como consecuencia de una circulación más meridiana de lo habitual del Vórtice circumpolar, que había permitido un paso muy reiterado de situaciones frontales. Haciendo un estudio de la dinámica atmosférica acontecida en los seis meses largos que median desde el 1 de septiembre de 2000 al 7 de marzo de 2001, la secuencia de tipos de tiempo habida es bien expresiva de lo arriba apuntado (Cuadro VIII).

A diferencia de otros años, los tipos de tiempo de carácter anticiclónico habían tenido escasa presencia. Una sola situación de cresta sahariana ocurrida del 7 a 10 septiembre, otra dinámica mixta con predominio anticiclónico, cinco crestas tropicales marinas $(\mathrm{Tm})$ amplias, cuatro con paso zonalizado de frentes por el norte de España y la misma proporción de cuñas del Suroeste. En total 16 situaciones repartidas en 49 días que representan el $26,1 \%$ de este período.

Cuadro VIII

TIPOS DE TIEMPO OCURRIDOS DEL 1-IX-2000 A 7-III-2001 EN CASTILLA Y LEÓN

\begin{tabular}{|c|c|c|}
\hline Tipo de tiempo & $\mathbf{N}^{\circ}$ Situaciones & Número de días \\
\hline Cresta Tm amplia & 5 & 20 \\
\hline Cresta Tm del suroeste & 4 & 8 \\
\hline Cresta Tm con paso circulación zonal al norte & 4 & 12 \\
\hline Cresta Tc & 1 & 4 \\
\hline Dinámica mixta (Cresta Tm al O y Vag. Pm al E.) & 2 & 5 \\
\hline Vaguada Pm al Norte de la Península Ibérica & 5 & 11 \\
\hline Vaguada Pm al Oeste & 9 & 23 \\
\hline Vaguada Pm centrada & 8 & 23 \\
\hline Vaguada Pm en zona de entrada & 4 & 12 \\
\hline Dinámica mixta (Vag. Pm al O y Cresta Tm al E.) & 9 & 29 \\
\hline Vaguada Am centrada & 3 & 6 \\
\hline Circulación zonal inversa & 4 & 9 \\
\hline Circulación zonal del Oeste & 1 & 1 \\
\hline Circulación zonal del Noroeste & 1 & 1 \\
\hline Gota Fría Pm al Norte & 2 & 5 \\
\hline Gota Fría Pm al Oeste & 1 & 5 \\
\hline Gota Fría Pm al Suroeste & 2 & 5 \\
\hline Gota Fría Pc al Suroeste & 2 & 4 \\
\hline Gota Fría Pm al E & 2 & 5 \\
\hline
\end{tabular}

Fuente: Boletines Meteorológicos Diarios. INM. 
En cambio, las situaciones inestables sobre Castilla y León habían sido mucho más frecuentes. Las que produjeron frío fueron escasas, pues tan sólo acontecieron dos retrógrados y dos coladas Am centradas sobre la Península. En cambio, el dominio de vaguadas de aire Pm de distinta localización (26 situaciones desarrolladas en 69 días) y de circulaciones zonales del oeste y noroeste (12 situaciones en 35 días) fue muy elevado. En conjunto los tipos de tiempo ciclónicos ocuparon 139 días, un 73,9\% de este otoño-invierno (Cuadros VIII y IX).

Cuadro IX

$N^{o}$ DE DÍAS DE LAS DISTINTAS SITUACIONES DINÁMICAS POR MESES (Período 1-IX-2000 a 7-III-2001)

\begin{tabular}{|l|c|c|c|c|c|c|c|c|c|}
\hline & Sep. & Oct. & Nov. & Dic. & Ene & Feb. & Mar & Total & $\%$ \\
\hline Circulación Sur-Norte & 14 & 14 & 4 & 5 & 5 & 7 & & 49 & 26,1 \\
Circulación Norte-Sur & 15 & 11 & 18 & 18 & 11 & 7 & 3 & 83 & 44,1 \\
Circulación Zonal & - & - & 8 & 7 & 14 & 2 & 4 & 35 & 18,6 \\
Circulación Inversa & - & - & - & - & - & 4 & - & 4 & 2,1 \\
Gotas Frías & 1 & 6 & - & 1 & 1 & 8 & - & 17 & 9,1 \\
\hline
\end{tabular}

Fuente: Boletines Meteorológicos Diarios. INM.

Fueron un otoño e invierno muy lluviosos — pero en la montaña también nivosos-, que permitieron ya a las alturas del mes de marzo unos suelos saturados y con escaso poder de infiltración, favoreciendo una escorrentía superficial acelerada hacia los ríos. Éstos, por su parte, vieron incrementado sus caudales respecto a otros años, ampliando la anchura de sus cauces, y rebosando hacia los lechos en aquellos momentos en que las precipitaciones fueron más intensas.

- También hay que considerar el papel tan discutido que han tenido los embalses de cabecera en esta situación. Es un hecho cierto que los embalses durante esta época del año tienen una reducida capacidad de laminación, y un nulo efecto sobre las precipitaciones que se producen aguas abajo de los mismos. Pero también es cierto que deben tener cierta capacidad de previsión ante posibles acontecimientos como el ocurrido.

Como consecuencia de las abundantes precipitaciones caídas a lo largo del invierno los embalses de la montaña palentina, Camporredondo y Compuerto sobre el Carrión, y Requejada, Ruesga (río Rivera) y Aguilar de Campoó sobre el Pisuerga, se encontraban prácticamente al límite de sus posibilidades, muy por encima de lo que marca la Comisión de Desembalses. La capacidad de resguardo era inadecuada. Sin embargo, los desembalses, que terminaron practicándose a fin de garantizar el margen de seguridad de las presas, a nuestra manera de ver, se realizaron tarde. Los de mayor envergadura tuvieron lugar escasos días antes de producirse la inundación, y coincidiendo en un momento en que las precipitaciones de cabecera eran realmente elevadas. Prácticamente lo que entraba era lo que salía, sino era algo más.

Esto motivó que muchas de las críticas se hayan dirigido en esta línea, hasta el punto de responsabilizar a las sueltas de agua del excesivo incremento de caudal de los ríos, y por ende, de la inundación. Para la CHD los desembalses agravaron la situación en un $7 \%$ al 
estimar que la cantidad de agua que se desembalsaba desde Compuerto, Aguilar y Arlanzón, representaba $200 \mathrm{~m}^{3} / \mathrm{seg}$, frente a la punta de $2682 \mathrm{~m}^{3} / \mathrm{seg}^{13}$. Desde luego que estas sueltas contribuyeron, pero no fue ni mucho menos el factor desencadenante.

Sí parece lógico pensar que unos desembalses más graduados en el tiempo y realizados desde mucho tiempo antes habrían minimizado bastante este riesgo. De hecho, la Confederación mantiene que los venía practicando a lo largo de todo el invierno. Sin embargo, el embalse de Aguilar vertía sobre el Pisuerga desde el lunes (día 5) un caudal de 90 $\mathrm{m}^{3} / \mathrm{segundo}$, más de lo habitual; y el de Compuerto si en principio entraba $150 \mathrm{~m}^{3} / \mathrm{seg}$ y desembalsaba $50 \mathrm{~m}^{3} / \mathrm{seg}$, más tarde la CHD tuvo que incrementarlo a $75 \mathrm{~m}^{3} / \mathrm{seg}$, lo que motivo entre otras cosas la inundación de Saldaña.

Se ha criticado mucho este comportamiento de la Confederación acusándola de salvaguardar por encima de todo los intereses de las hidroeléctricas ${ }^{14}$. El no perder agua para la producción de energía, llevó a los embalses al límite de sus capacidades y cuando las sueltas se realizaron en cuantías nada despreciables, coincidieron en un momento de abundantes lluvias lo que contribuyó a las numerosas inundaciones a lo largo del valle del Pisuerga.

- Otro factor a considerar que justifica que el río Pisuerga motive situaciones de peligro sobre Valladolid radica en la propia ubicación de esta ciudad. Localizada en el tramo bajo de su curso fluvial, constituye zona de paso obligado cuando el río concentra ya los caudales de todos sus afluentes, en estas fechas igualmente crecidos.

Días antes de la inundación la situación ya había sido difícil en Palencia ante el incremento de caudal del Carrión, que se desbordó en varios puntos de la ciudad y afectó al Parque Huertas del Obispo y al complejo deportivo Parque Isla Dos Aguas. En la provincia de Burgos el reiterado desbordamiento del Pisuerga en Melgar de Fernamental causó el corte de la carretera N-120 además de otras locales como la BU-7010 en Quintanapalla y la BU-6210 en el valle de Valdelucio.

Así pues, las aguas crecientes de muchos arroyos y afluentes del Pisuerga se fueron lentamente adicionando siguiendo todo un proceso de jerarquización antes de cederlas finalmente al Duero. Por esta razón los mayores daños se produjeron no en la cabecera de su valle donde tiene su nacimiento, que es donde más llueve y existe menos población, sino en su curso bajo, sobre las llanuras, donde se asientan la mayor parte de los núcleos de población, aunque llueva menos.

Por lo tanto, la situación vivida el 6 de marzo de 2001 se ha encontrado con todos los factores propicios para su consecución: un otoño-invierno con abundantes precipitaciones, unos procesos de deshielo rápidos y muy efectivos, unos suelos saturados y encharcados, unos desembalses de agua tardíos y abundantes y un solapamiento de caudales muy crecidos de varios colectores. No obstante, no hay que olvidar que esta situación por compleja que parezca por el número de factores que intervienen, no es en absoluto extemporánea ni extraña, sino un proceso natural de los muchos que caracterizan a Castilla y León.

13 Periódico $A B C$ Valladolid, edición del día 11 de marzo de 2001. Cfr. pág. 34.

14 El procurador socialista Antonio Losa consideró que «no han sido las lluvias las culpables de lo ocurrido sino la pésima gestión de los embalse de la región»......«Teniendo en cuenta que los ríos que se han desbordado son los que están regulados por un mayor número de embalses, hay que pensar que no se ha jugado bien con la gestión de los mismos, sino que se ha supeditado a intereses hidroeléctricos» Según aparece en el periódico $A B C$ Valladolid del día 8 de marzo. 


\section{Los efectos de las inundaciones en Valladolid y en otros puntos de la región}

El desbordamiento del Pisuerga en Valladolid el 6 de marzo, más que inundación, pues éste no llegó a ocupar los límites de su lecho mayor, trajo como consecuencia la afectación de aquellas áreas que por la propia geometría del río cabría esperar que se anegasen. Así cubrió los tramos más bajos de sus riberas, pero ocupando sobre todo los lóbulos de los meandros que dibuja en su discurrir a la entrada y salida de la ciudad. Este hecho unido al carácter disimétrico del valle del Pisuerga, justifican que las peores consecuencias se cen-

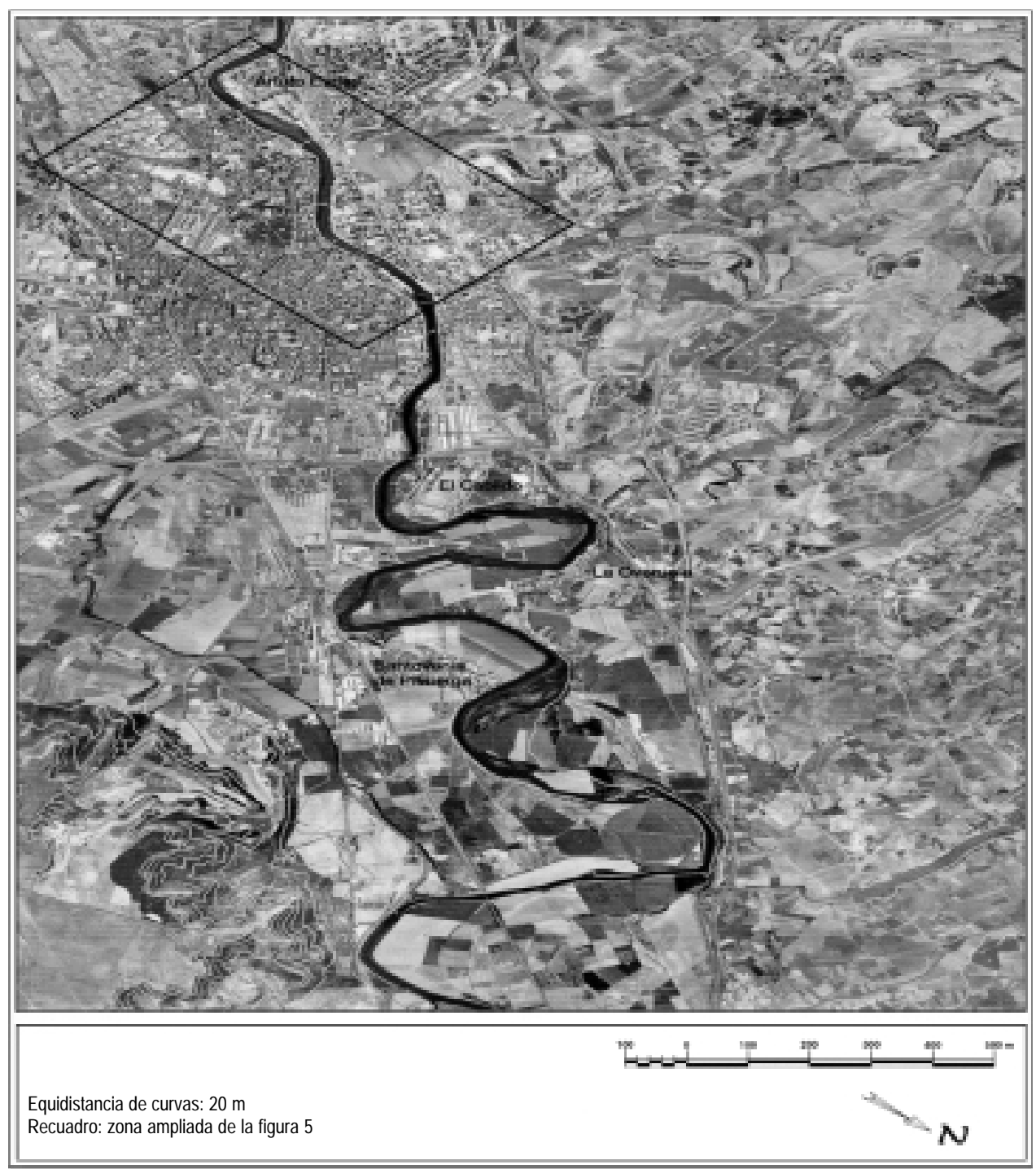

FIGURA 4. El valle del Pisuerga aguas arriba de Valladolid. 
traran en el tramo de meandros de El Cabildo-La Overuela, y en el lóbulo ocupado en su mayor parte por el barrio de Arturo Eyries (Fig. 4).

El cauce de río cuando entra en la ciudad sigue la cota de $685 \mathrm{~m}$, manteniéndola hasta poco antes del Puente de G. Regueral (Poniente) donde se profundiza algo. A partir de este punto y en el resto de su recorrido urbano circula a $680 \mathrm{~m}$, con lo que apenas se encaja unos $5 \mathrm{~m}$ en su travesía urbana (Fig. 5). Los espacios cubiertos por el agua alcanzaron, según sectores, las curvas de nivel comprendidas entre 685 y $690 \mathrm{~m}$, ocupando sus dos terrazas más bajas de las seis datadas en su extenso valle. Siempre la ocupación del agua fue más extensa en aquellos puntos donde su cauce no está canalizado y la vega es más extensa. Pese a todo, ocupó algunos de los parques ribereños como el de las Moreras y la Rosaleda, amén de numerosas instalaciones localizadas en enclaves de alto riesgo y dentro de la zona de policía, caso de instalaciones deportivas y viviendas (Cuadro $\mathrm{X}$ ).

Tan enorme listado de consecuencias son cuestiones que se deberían tener muy en cuenta en cualquier proyecto de planificación y ordenación de este espacio urbano. No hay que olvidar que las inundaciones son de todos los riesgos climáticos los que ocasionan mayores daños en la región. Habría que invertir más en ello.

Valladolid en su proceso de crecimiento ha ido poco a poco flanqueando el cauce fluvial, y ocupando sectores de su lecho menor, siempre dentro de las normas urbanísticas. Desde la inundación de 1962 el cuidado de la margen izquierda del Pisuerga fue motivo de atención por parte de distintos equipos municipales lo que motivó, entre otras intervenciones, la construcción del muro de las Moreras. No obstante, sorprenden actuaciones posteriores de rehabilitación y aprovechamiento de sus márgenes y terrenos próximos, como la puesta en marcha del Museo de la Ciencia (los destrozos de sus sótanos ahora se han evaluado en 80 millones de pesetas), la restauración del emblemático edificio Duque de Lerma, cuyos bajos están realmente próximos al agua, o muchas de las urbanizaciones que han ido surgiendo aguas arriba (La Overuela, El Cabildo) y abajo de la ciudad (El Pichón, Entrepinos, la Vega, Camino de Badarroyo y las Aceñas en Simancas).

Esta avenida ha contribuido por lo tanto, a poner de manifiesto algunas de las sombras de la Ley de Urbanismo. La Junta de Castilla y León, el Ayuntamiento de Valladolid y la CHD reconocen que la normativa es farragosa y de difícil traducción. Para ellos no está claro el concepto de «zona inundable», ni quién decide a qué distancia se edifica. Lo que sí parece evidente es que todo lo construido es legal, pues en el momento en que se edificó se ajustaba a la normativa.

La Ley de Urbanismo de la Comunidad de Castilla y León (Ley 5/1999) establece que los terrenos próximos al cauce de un río son suelo rústico, existiendo diferentes categorías de suelo a los que se le otorgan distintos grados de protección. Los terrenos amenazados por riesgos naturales, tales como inundación, entrarían dentro de la categoría de suelos rústico con protección especial. Sobre ellos los particulares no pueden construir, pero sí puede hacerlo la Administración pública si su actuación deriva de la aplicación de la normativa sectorial o del planeamiento urbanístico ${ }^{15}$. Por su parte, la ley de Aguas de 1985 sostiene que es la Confederación la encargada de autorizar o rechazar cualquier tipo de construcción, no pudiendo hacerse dentro de la denominada zona de policía que se estima en 100 $\mathrm{m}$ a ambos lados de las orillas del cauce. A este respecto, la Consejería de Fomento indica que el organismo de la Cuenca debe tener presentes las anteriores crecidas del Pisuerga en

15 Ley 5/1999 de 8 de abril, de Urbanismo de Castilla y León. BOC y L Nº 70. Cfr. pp. 4076 y ss. 
Cuadro X

CONSECUENCIAS DE LA INUNDACIÓN DEL 6-III-2001 EN VALLADOLID Y SU ENTORNO

\begin{tabular}{|c|c|}
\hline $\begin{array}{l}\text { Desalojos de } \\
\text { viviendas }\end{array}$ & $\begin{array}{l}\text { - } 4 \text { familias en La Overuela (calles de las Leyes y Camino del Espinar) } \\
\text { - } 2 \text { familias en Soto de Medinilla } \\
\text { - En Arturo Eyries rescates en zodiac desde las } 7 \text { h (calles Ecuador, Avda. República Argentina) } \\
\text { - El bloque n1 } 5 \text { de la calle Francisco Mendizábal es desalojado por precaución ante posible derrumbe } \\
\text { al afectarle a la cimentación de la casa un desprendimiento de tierra habido en un tramo del cauce del } \\
\text { Pisuerga. Quedan en la calle unas } 200 \text { personas }\end{array}$ \\
\hline $\begin{array}{l}\text { Urbanizaciones } \\
\text { afectadas }\end{array}$ & $\begin{array}{l}\text { - La Overuela, El Cabildo a la entrada de la ciudad } \\
\text { - El Pichón, Entrepinos, la Vega, Camino de Badarroyo y las Aceñas (Simancas) }\end{array}$ \\
\hline Calles cortadas & $\begin{array}{l}\text { - Arturo Eyries: Plaza de Cuba, Paseo de Argentina, Lucayas, Chile } \\
\text { - Calle Lorenzo Hurtado, entre Joaquín Velasco Martín y José Cantalapiedra } \\
\text { - Puente Mayor desde las 9h. (día 6) hasta las 5,30 h. de la madrugada (día 7) }\end{array}$ \\
\hline $\begin{array}{l}\text { Aparcamientos } \\
\text { inundados }\end{array}$ & $\begin{array}{l}\text { - Dos plantas de aparcamientos del n }{ }^{\circ} 2 \text { de Francisco Suárez, afectando a } 70 \text { vehículos } \\
\text { - Edificio Duque de Lerma }\end{array}$ \\
\hline $\begin{array}{l}\text { Centros culturales } \\
\text { y deportivos }\end{array}$ & $\begin{array}{l}\text { - Museo de La Ciencia } \\
\text { - Polideportivo del Pisuerga. El agua subió hasta casi dos metros }(1,7 \mathrm{~m}) \\
\text { - Complejos de piragüismo Narciso Ibáñez, Pisuerga y Tenerías } \\
\text { - Playa de las Moreras } \\
\text { - Complejo deportivo Juan de Austria. } \\
\text { - Rockódromo de la plaza de Méjico } \\
\text { - Dos campos de fútbol en Soto de Medinilla }\end{array}$ \\
\hline Zonas ajardinadas & $\begin{array}{l}\text { - La Rosaleda, zona de las Moreras, Paseo Isabel La Católica } \\
\text { - Valle de Arán, Parque Ribera de Curtidores y Parque Ribera de Castilla }\end{array}$ \\
\hline $\begin{array}{l}\text { Cortes de luz, (desde } \\
\text { las } 5 \text { de la madrugada) } \\
\text { y de agua }(*)\end{array}$ & $\begin{array}{l}\text { - Arturo Eyries }(*) \\
\text { - Edificio Duque de Lerma } \\
\text { - Diversas urbanizaciones }(*) \\
\text { - Huerta del Rey } \\
\text { - Parquesol }\end{array}$ \\
\hline Colegios cerrados & $\begin{array}{l}\text { - Casa cuna de la Diputación, Núñez de Arce, Rosa Chacel, Jorge Guillén, Antonio Tobar, Jorge Guillén. } \\
\text { Más de } 3000 \text { escolares de la ciudad disfrutaron de un día inesperado de vacaciones }\end{array}$ \\
\hline Colapso de tráfico & $\begin{array}{l}\text { - Por los cortes del puente Mayor y diversas calles de la ciudad aunque el caos ya venía de días previos } \\
\text { por el corte del } \mathrm{P}^{\mathrm{o}} \text { de Isabel la Católica. No obstante ese día se intensificó, sobre todo en el centro de } \\
13 \text { a } 15 \text { horas, y en barrios próximos al cauce del río como La Victoria, Huerta del Rey y la zona de } \\
\text { Curtidores, asimismo repercutió en gran medida en todo el } \mathrm{P}^{\circ} \text { de Zorrilla y la Avda. de Salamanca } \\
\text { (fuertes retenciones) } \\
\text { - También el transporte público sufrió los efectos al tener que cambiarse la ruta habitual de algunas líneas } \\
\text { de Bus (líneas } 7 \text { y SC) }\end{array}$ \\
\hline $\begin{array}{l}\text { Desprendimientos } \\
\text { de tierra }\end{array}$ & $\begin{array}{l}\text { - Producidos en un sector de la margen derecha del cauce del Pisuerga como consecuencia de la crecida } \\
\text { y posterior reducción del caudal. La disminución de la presión hidrostática sobre dicha ladera unido a } \\
\text { la fuerza del agua del río permitió el desplome de buena parte de la vertiente quedando al descubierto } \\
\text { la cimentación de un edificio de once plantas sito en la calle Francisco Mendizábal, el cual tiene que } \\
\text { ser desalojado por precaución ante posible derrumbe. El río arrastró parte de un muro filtrándose el } \\
\text { agua por sus cimientos. Se trata de un edificio con viejos problemas pues ya en } 1989 \text { se invirtieron un } \\
\text { total de } 170 \text { millones de pesetas para su arreglo del que los vecinos aún hoy día protestan por no estar } \\
\text { terminado. Son tres bloques de viviendas sociales construidas en } 1982\end{array}$ \\
\hline $\begin{array}{l}\text { Empeoramiento de } \\
\text { la calidad del agua }\end{array}$ & $\begin{array}{l}\text { - El canal de Castilla, que suministra agua a buena parte de la capital, fue invadido por el Carrión. } \\
\text { La depuradora de las Eras (Canal de Castilla) y la de San Isidro (Canal del Duero) están a pleno } \\
\text { rendimiento, habiendo aumentado esta última su potencia para compensar el déficit de pureza de la } \\
\text { otra. Desde Agualid comunican «que el grado de contaminación que llegue a casa será mínimo» }\end{array}$ \\
\hline $\begin{array}{l}\text { Deterioro de viales } \\
\text { y bajos comerciales }\end{array}$ & — Fundamentalmente en Arturo Eyries, barrio más afectado \\
\hline
\end{tabular}

Fuente: Periódicos El Norte de Castilla, ABC Valladolid, y El Día de Valladolid. 


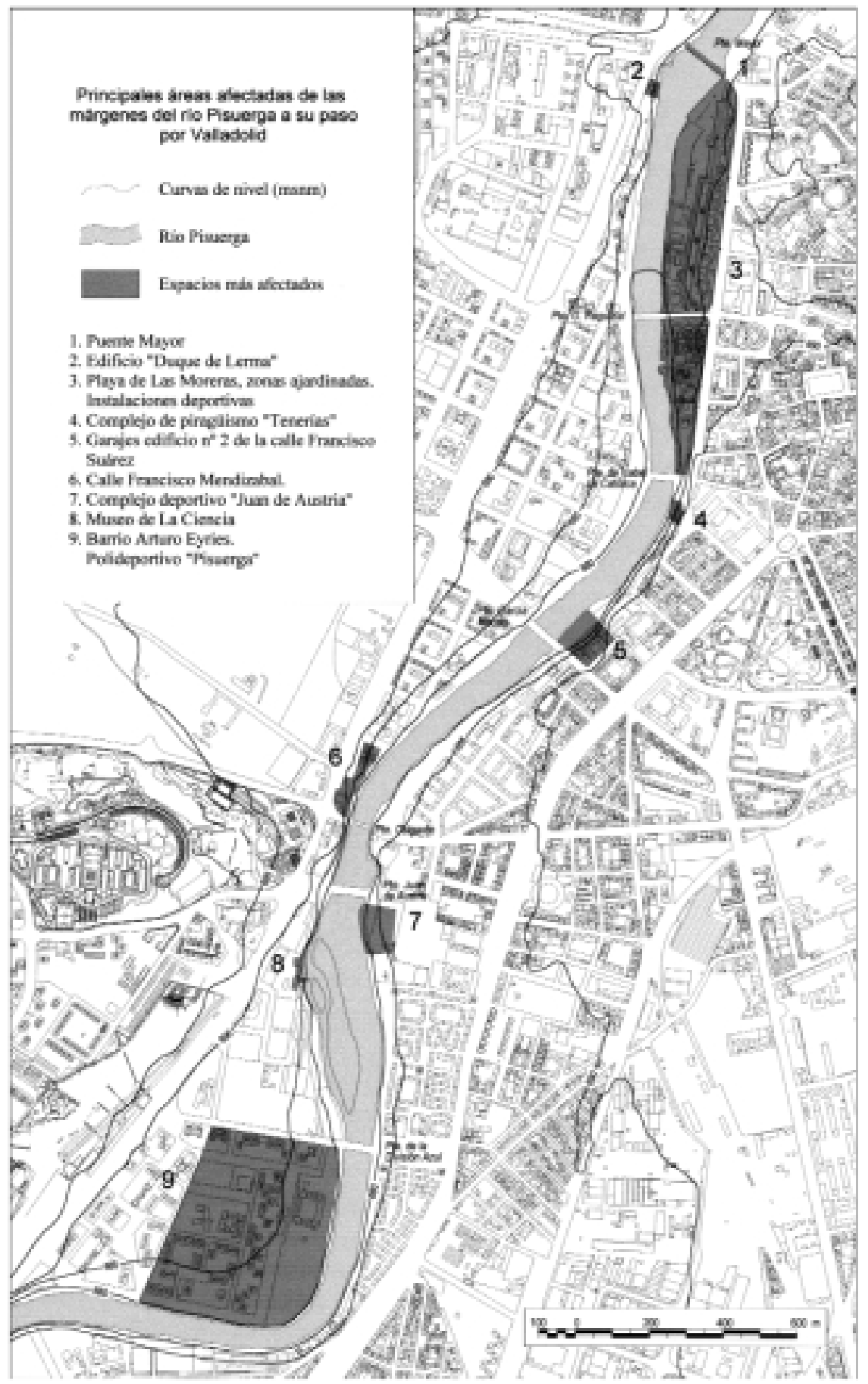

FIGURA 5. Inundación de 6 de marzo de 2001. 
su toma de decisiones y así decidir en qué sitios se puede edificar y en cuáles no por peligro de desbordamiento. Lo cierto es que aún a estas alturas no existe ningún mapa de zonas inundables para la provincia ni mucho menos para la región, sólo para esta última un trabajo avanzado de la CHD en colaboración con Protección Civil.

Tampoco parece claro que exista un criterio bien definido sobre cómo intervenir sobre lo ya construido en zonas de riego, si proceder a una remodelación urbana que implique una sustitución progresiva sobre su uso o dejarlo como está ${ }^{16}$. Lo ocurrido con el polideportivo Pisuerga puede arrojar una luz en este sentido. En lugar de optarse por su traslado a otro lugar se han emprendido las obras de restauración. ¿Supone esto la asunción de pérdidas futuras para una crecida similar? Mientras éstas sólo sean económicas, bien vamos... Otro caso parejo es el edificio Duque de Lerma, durante tantos años abandonado, pancarta de quejas de la ciudad, en lugar de la tan anunciada demolición se ha terminado optando por su incomprensible rehabilitación.

La inundación del 6 de marzo en Valladolid ha sido espectacular, pero sobre todo por desarrollarse en una gran ciudad que no por los efectos reales que ha producido la subida del agua. Si éstos se analizan, tampoco han sido tantos ni tan dramáticos (a excepción de lo que consideren los directamente afectados). Como decíamos, sólo los esperados en estos casos. Más llamativa y lamentable ha sido la falta total de previsión y de información con que se ha producido, lo que ha hecho destapar muchos de los problemas que subyacen dentro de la Administración y demás organismos responsables.

Pero no sólo esta ciudad ha sido la única ni la más perjudicada este invierno con las inundaciones. Más numerosas y muchas veces con peores efectos las ha habido en otros puntos de la provincia e incluso de la región (Cuadro XI). Días antes de que se produjera en Valladolid, las provincias de Palencia, León y Burgos eran las más afectadas y pocas horas después, cuando los caudales llegaron al Duero, fueron la campiña toresana y la Tierra de Zamora las más dañadas.

Las consecuencias de estos episodios en la región y a modo de breve síntesis pueden reducirse a desbordamientos de cursos fluviales, anegamiento de campos de cultivo con elevadas pérdidas para las cosechas, destrucción de numerosas conducciones de agua para riego, desprendimientos en carreteras y vías férreas y roturas de puentes.

Lo cierto es que estos episodios, de los que se han enumerado los más señalados, han causado graves daños en la región. Según informaciones aparecidas en la prensa de esos días, el primer cálculo del balance de pérdidas realizado por la Junta de Castilla y León se cifraba en unos 5.000 millones de pesetas. Por su parte, en Valladolid el primer balance municipal elevaba los daños a 200 millones. La Diputación provincial lo hizo en 115 millones para la provincia. Los daños en la provincia de Zamora sólo para el mes de diciembre superaron los 1.800 millones de pesetas, cifra inferior de lo estimado para la última crecida. En ella, el Duero anegó casi 800 millones de pesetas del reciente Plan de recuperación de riberas de la capital.

La COAG cifró en 3.000-4.000 millones los daños en la agricultura y ganadería, si bien las pérdidas en conjunto pueden sumar los 10.000 millones de pesetas si se añaden las derivadas de las cosechas perdidas de cereal y de las infraestructuras (caminos rurales). Las mayores pérdidas se centraron en el maíz y la remolacha. Un 75\% de las más de $60.000 \mathrm{Ha}$ de maíz estaban sin recoger en León (primera provincia productora de la región y una de

16 Aunque exista un Plan de Rehabilitación de las márgenes del río, éste en dos años de aplicación hasta ahora sólo ha emprendido tareas de acondicionamiento recreativo más que de remodelación urbana. 


\section{Cuadro XI \\ PRINCIPALES CONSECUENCIAS DE LAS INUNDACIONES EN CASTILLA Y LEÓN DURANTE EL INVIERNO 2000-2001}

\begin{tabular}{|c|c|}
\hline $\begin{array}{l}\text { Inundaciones de } \\
\text { sótanos y viviendas } \\
\text { particulares }\end{array}$ & $\begin{array}{l}\text { - En Santovenia y Simancas (Pisuerga) y en Mayorga de Campos (Cea), } \\
\text { - En Tordesillas (Duero) se inundó por quinta vez en lo que va de invierno el restaurante Da Carmen. } \\
\text { - Herreros, Pollos, San Román de Hornija, Fresno de la Ribera (Duero) } \\
\text { - En Zamora (Duero), los barrios de Olivares, Villagodio y La Rinconada, así como la carretera de Entre } \\
\text { puentes, la zona de los Pelambres, y el camino viejo de Villaralbo. }\end{array}$ \\
\hline $\begin{array}{l}\text { Anegamiento de } \\
\text { campos de cultivo } \\
\text { y granjas }\end{array}$ & $\begin{array}{l}\text { - El Duero en Simancas, Tordesillas, Herreros, Pollos, Castronuño, Villafranca de Duero, San Román de } \\
\text { Hornija, Vega de Toro, Peleagonzalo, Fresno de la Ribera, Villalazán, Villaralbo y Zamora. } \\
\text { - Desbordamientos en la comarca de Benavente-Los Valles. } \\
\text { - Desbordamiento del Cúa en Villadepalos y del A }{ }^{\circ} \text { de Los Barredos en Camponaraya (León). Enchar- } \\
\text { camientos en campos de frutales en el Bierzo (con aparición de «filoctora», que afectó a los manzanos } \\
\text { de la variedad reineta y golden.) } \\
\text { - Desbordamiento del Jamuz en Quintana de Marco y del A }{ }^{\circ} \text { Valdearcos (León) } \\
\text { - El río Omaña desbordado en Llamas de la Ribera, S. Román de los Caballeros, Villaviciosa de la } \\
\text { Ribera, Pedregal y Santiago de Molinillos, por la falta de encauzamiento del tramo de } 7 \text { km que hay } \\
\text { entre San Martín de la Falamosa y su desembocadura en el Órbigo. } \\
\text { - El Cea se desborda en Sahagún y Mayorga de Campos } \\
\text { - Área de Castroponce (Valladolid) por inundación del Valderaduey } \\
\text { - Numerosos daños del Pisuerga en Melgar de Fernamental } \\
\text { - El río Carrión crece en Palencia creando problemas en Soto de Cerrato y Husillos. }\end{array}$ \\
\hline Agua no potable & $\begin{array}{l}\text { - En la Bañeza ( } 12.000 \text { habitantes) por la crecida del río Órbigo, séptima vez desde diciembre. } \\
\text { - En Benavente corte de suministro dado que el Órbigo anegó las instalaciones de la planta potabiliza- } \\
\text { dora que abastece a este núcleo. }\end{array}$ \\
\hline $\begin{array}{l}\text { Desprendimientos } \\
\text { de tierra ocasionados } \\
\text { por las abundantes } \\
\text { precipitaciones }\end{array}$ & $\begin{array}{l}\text { - En El Bierzo: autovía del Noroeste en la salida este de Ponferrada (Km. 386-387 dirección La Coruña). } \\
\text { El carril de la A-6 en Carracedelo (km 388) y el carril dirección Madrid entre las salidas de Campona- } \\
\text { raya y Carracedelo. Al oeste de Barjas y Balboa varias carreteras locales presentan caídas de taludes de } \\
\text { tierra. En Bembibre y Ponferrada (A-6). LE-611 en el término municipal de Cebanico. En un pinar de } \\
\text { Saldaña fue obligado desalojar a tres viviendas unifamiliares } \\
\text { - En la provincia de Palencia la zona de Gama. } \\
\text { - En Modúbar de la Cuestas (BU-P-8012). En Cabia en el Km } 2 \text { de BU-V-1003 se ha hundió un puente } \\
\text { sobre el Arlanzón. } \\
\text { - En Valladolid el desprendimiento de parte de la pared del lecho fluvial del Pisuerga a su paso por la } \\
\text { ciudad. Varios tramos de la carretera comarcal VA-103 que une Valoria la Buena con la N-620. De } \\
\text { Castronuño a Villafranca de Duero. De Saelices de Mayorga a Albires. }\end{array}$ \\
\hline $\begin{array}{l}\text { Carreteras cortadas } \\
\text { por agua en la } \\
\text { calzada }\end{array}$ & $\begin{array}{l}\text { - La } 5004 \text { de Castromonte a Villagarcía. } \\
\text { - La V.P.5505 de Medina de Rioseco a la Unión de Campos por Bolaños. } \\
\text { - VA-101 de Pesquera de Duero a Villafuerte de Esgueva. } \\
\text { - Puente del Pisuerga en Simancas. VA-P-9801. } \\
\text { - Puente sobre el río Valderaduey en Becilla. } \\
\text { - De la Mudarra a Castromonte, De Castromonte a Villabrágima. De Vega de Ruiponce a Santervás, De } \\
\text { Peñafiel a Cogeces del Monte. } \\
\text { - De Castronuño a Toro y a San Román de Hornija. } \\
\text { - De Toro a Zamora por Peleagonzalo, Villalazán y Villaralbo. } \\
\text { - La que une Benavente y Milles de la Polvorosa, Coreses y la C-612, y ésta con Molacillos. La N-122 } \\
\text { a la Granja Florencia. Manganeses de la Polvorosa y Villabrázaro y Fuentes del Ropel y Villafer en } \\
\text { León. Cea-Bustillo de Cea; Bustillo de Cea-Saelices del Río. Ardón-Santa Mª del Páramo (Valdevimbre, } \\
\text { Valderas y Reliegos). Puente sobre el Cea en Melgar de Abajo. } \\
\text { - No se puede circular por Mansilla de las Mulas, Alija del infantado (LE-114), Valcavado (LE-412) } \\
\text { y Valdevimbre. LE-910 en Santas Martas. LE-000 en Valdebimbre y LE-511 en Villafer. } \\
\text { - C-619 en Reinoso de Cerrato (Palencia). }\end{array}$ \\
\hline $\begin{array}{l}\text { Corte de la línea } \\
\text { férrea }\end{array}$ & $\begin{array}{l}\text { - Entre Dueñas y Venta de Baños, durante varias horas por la mañana, ya que el agua se adueñó de la } \\
\text { línea Madrid-Irún. El corte afectó a seis trenes de viajeros y a } 30 \text { de mercancías a lo largo de la noche. } \\
\text { - Espectacular accidente de un tren de mercancías a su paso por Veguellina de Órbigo al derrumbarse un } \\
\text { puente por la crecida del río. Se produjo el derrumbe de tres cisternas cargadas de cemento. La } \\
\text { compañía ferroviaria había limitado a } 20 \mathrm{Km} / \mathrm{h} \text { la velocidad de los trenes que circulaban por dicho } \\
\text { puente existiendo en este punto un sistema de «vigilancia permanente». Llama la atención que a } \\
\text { principios de febrero se hundiera también el puente que comunica este núcleo con el páramo, y el } 5 \text { de } \\
\text { enero el peatonal de Villamor de Órbigo. En dos meses las crecidas del Órbigo se han llevado tres puentes } \\
\text { en apenas } 5 \mathrm{~km} \text {. }\end{array}$ \\
\hline
\end{tabular}

Fuente: Periódicos El Norte de Castilla, ABC Valladolid, y El Día de Valladolid.

Investigaciones Geográficas, nº 27 (2002) 
las mayores de España), con lo que se esperaba perder hasta un $40 \%$ de la producción de 2001. Unas $150.000 \mathrm{Tm}$ de remolacha estaban sin recolectar, pues la campaña había comenzado este año más tarde por el mal tiempo. Además, esta situación impidió que las parcelas quedaran libres a tiempo para las siembras en muchas de las vegas de los ríos Órbigo, Esla y Cea y a los que habían plantado cereal, se les pudrieron las semillas al encharcase las tierras y los que no lo hicieron, ahora era difícil por el exceso de agua que tenían. Por su parte, los sindicatos agrarios (ASAJA, COAG y UPA) pidieron que la Tierra de Campos se declarara zona catastrófica ante las crecidas de los ríos Cea y Valderaduey ${ }^{17}$.

Por su parte, el Consorcio de Compensación de Seguros ha estimado que las pérdidas en los bienes asegurados para Castilla y León, en los episodios de inundación habidos a lo largo de este último invierno, se elevan a unos dos mil millones de pesetas (CUADRO XII). De ellos, algo más de la mitad - 54,5\%—, corresponden sólo en la provincia de Valladolid, gracias a la mayor incidencia de las desarrolladas en el mes de marzo.

Cuadro XII

SINIESTRALIDAD ESTIMADA DE LOS EPISODIOS DE INUNDACIÓN DEL INVIERNO 2000-2001 EN CASTILLA Y LEÓN (a junio de 2001)

\begin{tabular}{|c|c|c|c|r|}
\hline \multirow{2}{*}{ Período } & \multicolumn{2}{|c|}{$\mathbf{N}^{\mathbf{0}}$ de Expedientes estimados } & \multicolumn{2}{c|}{ Importe estimado (pts. corrientes) } \\
\cline { 2 - 5 } & Castilla y León & Valladolid & Castilla y León & Valladolid \\
\hline 5-XII a 21-XII & 350 & 50 & 105.000 .000 & 10.000 .000 \\
5-I & 225 & 25 & 72.000 .000 & 8.500 .000 \\
26-I a 29-I & 310 & 30 & 177.000 .000 & 500.000 \\
7-II a 8-II & 190 & 10 & 26.500 .000 & 1.100 .000 .000 \\
3-III a 24-IV & 2.030 & 1.300 & 1.720 .000 .000 & 1.144 .000 .000 \\
\hline Total & 3.105 & 1.415 & 2.100 .500 .000 & \\
\hline
\end{tabular}

Fuente: Consorcio de Compensación de Seguros.

La respuesta del Consejo de Ministros a estos hechos fue aprobar un decreto el día 9 de marzo de 2001, por el se concedían 1500 millones de pesetas para reparar los daños producidos por las últimas lluvias en las Comunidades autónomas de Castilla y León, Galicia, Andalucía Valencia, Aragón y Cataluña. Este presupuesto se destinaba a recuperar las defensas de numerosas poblaciones que habían sido rebasadas o deterioradas por las crecidas. De éstos, 535 millones iban destinados de modo preferente a la Cuenca del Duero, 395 a la Cuenca del Norte y 270 a la del Ebro. El M $^{\circ}$ de Medio Ambiente tiene previsto invertirlos de manera inminente en la Cuenca del Duero para obras de emergencia (Cuadro XIII).

$\mathrm{Si}$ bien estas medidas vienen a paliar en parte los efectos de las inundaciones de este año, habría que señalar otra serie de actuaciones que incluso las podría hacer innecesarias en el futuro, tales como una prevención y protección más efectivas.

17 Según aparece en el diario ABC Valladolid del día 8 de marzo de 2001. Cfr. pp. 7. 
Cuadro XIII

DESTINO DEL PRESUPUESTO SEGÚN ZONAS (9 marzo 2001)

\begin{tabular}{|l|l|}
\hline Provincia de Soria & $\begin{array}{l}100 \text { millones de pts. para los núcleos de Vilviestre de los Nabos, } \\
\text { Langosto, Hinojosa de la Sierra, Molinos de Duero, Salduero y Garray. }\end{array}$ \\
\hline $\begin{array}{l}\text { Sistema Tera (ríos Tera, } \\
\text { Almucera, Castrón y Támega) }\end{array}$ & $\begin{array}{l}225 \text { millones para los municipios de Santa Croya de Tera, } \\
\text { Quiruelas de Vidriales, Burganes de Valverde, Olmillos de Valverde, } \\
\text { Brime de Urz, Verín, y Laza de las provincias de Orense y Zamora. }\end{array}$ \\
\hline $\begin{array}{l}\text { Sistema Tormes-Águeda } \\
\text { (ríos Tormes, Águeda }\end{array}$ & $\begin{array}{l}210 \text { millones de pts. para los núcleos de Ciudad Rodrigo, Aguda del } \\
\text { y Alhaudillo, Pedrosillo de los Aires, Fresno Alhándiga, Sieteiglesias de } \\
\text { Tormes, Adealengua y Zapardiel de la Ribera en las provincias de } \\
\text { Salamanca y Ávila. }\end{array}$ \\
\hline
\end{tabular}

\section{Algunas ideas para la reflexión}

La situación vivida en Valladolid en el mes de marzo ha puesto de manifiesto la gran cantidad de debilidades que presenta nuestro sistema de protección ante situaciones de riesgo natural. Muchas de ellas han venido provocadas por un mal diagnóstico de lo que estaba sucediendo y de lo que podía suceder. Y, evidentemente, a partir de un diagnóstico equivocado, las actuaciones tampoco serán las más apropiadas. Si además unimos a ello actitudes de desprecio, minusvalorando el riesgo, el problema se agrava.

De entre las primeras, las que hacen referencia al diagnóstico ya se han señalado bastantes al respecto. El conocimiento y valoración de la dinámica atmosférica y su funcionamiento en relación con la gestión del riesgo es una asignatura pendiente. Los esfuerzos se centran más en el conocimiento meteorológico y climático que en analizar sus efectos sobre el hombre, actividades y asentamientos. Y esta distinción se transmite a la administración. Unos se encargan de unas cosas y otros de otras pero no hay realmente una imbricación desde una perspectiva conjunta o común. Así mientras unos estudian el cielo otros estudian el suelo, y ambos parecen seguir líneas paralelas cuando no divergentes.

La primera medida a realizar sería aquella que encaminara actuaciones a analizar el comportamiento de la cuenca en su conjunto, a determinar cuáles son los mecanismos que en ella se producen y cuáles son sus respuestas. En definitiva al diagnóstico de los procesos del riesgo de forma integral. Sin conocerlos, no se puede actuar ni para prevenirlos ni para corregirlos.

Ahora bien, si en el diagnóstico cada uno anda por su lado, más aún sucede esto en la actuación, tanto para la alerta como para la protección. La atomización de la Administración más que corregir este problema, lo amplifica. Es cierto que la subordinación de actuaciones es necesaria, pero partiendo de la premisa de la jerarquía. A cada nivel, le corresponden unas posibilidades de actuación. Y no sólo por cuestiones de competencias, sino por otras de optimización de recursos y actuaciones. Así, la intervención sobre el medio físico y sus procesos requieren una valoración a dos niveles. Por una parte, desde la concepción integral de la cuenca y por otra, desde las actuaciones concretas en puntos clave o de especial relevancia. Unas y otras se desarrollan con dificultad, bien por problemas competenciales bien por problemas presupuestarios.

Pero es más, si estas situaciones como la de marzo de este año, podían haber visto minimizados sus efectos mediante unos adecuados sistemas de vigilancia, control y alerta, bien 
es cierto que hay otra serie de actuaciones que una vez disparado el proceso, podían dejarle sin efecto. Nos referimos a aquellas relacionadas con la ordenación del territorio.

En este tema son las Administraciones regionales y locales las que tienen responsabilidades. Ahora bien, si las normas de actuación urbanística son insuficientes, tampoco corrigen el problema. La planificación urbanística no incorpora el criterio del riesgo. $\mathrm{O}$ al menos no lo hace dándole la importancia que merece. En muchos casos, son simples consideraciones teóricas y no reales. No se cartografían en detalle las áreas de riesgo. Eso supone costes económicos. Y mucho menos, se actúa con criterio en ellas. La divina providencia será en último caso la responsable, o la Q500 y nunca el gestor local. Tampoco las directrices de ordenación territorial vienen a suplir estas carencias como exige la ley. El tratamiento del riesgo se confunde con el diagnóstico de la peligrosidad y éste además se hace de forma inexacta e imprecisa. El riesgo sigue siendo esa «coletilla» que hay que citar pero no abordar. El Medio Ambiente sigue siendo un elemento a proteger, y no del que también haya que protegerse.

Los efectos de la crecida en Valladolid se podrían haber minimizado si hubiera habido, por una parte, la prevención suficiente y las actuaciones consiguientes y por otro, si la ciudad no ocupara el espacio que le pertenece al río. Pero eso implica la restricción de los usos y, por tanto, un coste económico y probablemente político que pocos están dispuestos a asumir.

\section{Conclusiones}

Son numerosos los procesos de inundación ocurridos este último invierno en Castilla y León. Algunos de ellos han alcanzado en determinados momentos cierto grado de espectacularidad, caso de la del Pisuerga en Valladolid el 6 de marzo de 2001, del Duero en la vega de Toro y Zamora el día siguiente, del Órbigo a primeros de enero, febrero y marzo, y un largo etcétera.

Reparando en sus causas, son muchas e íntimas las relaciones que guardan con la dinámica atmosférica desarrollada en los últimos meses. Las abundantes precipitaciones durante el otoño-invierno de 2000-2001 han propiciado buena parte de ellas en diferentes puntos de la región, destacando las producidas sobre la red del Esla, Carrión y Pisuerga. Unas precipitaciones muy superiores a lo que es habitual en estas tierras, cifradas en 350$400 \mathrm{~mm}$ de septiembre a febrero, eleva altamente la probabilidad de que se produzcan.

Por su parte, los procesos de deshielo rápidos en la etapa final del invierno astronómico también las han permitido sobre el Carrión, Pisuerga y Duero. Siempre que haya nieve en las montañas cantábricas la llegada de aire templado o incluso cálido de la mano de circulaciones zonales del oeste la funden con tal premura que incrementan las situaciones de peligro.

Sin embargo, todo parece indicar que las inundaciones, independientemente del tipo que sean, se deben más a la duración de situaciones llovederas que no a la intensidad de las precipitaciones. Al menos en las que acontecen en el centro del invierno, que siempre están en clara relación con las circulaciones de alto índice zonal a las que se asocian el paso continuo de borrascas. Este comportamiento dinámico bien permite ir acumulando altos registros o bien acelera los procesos de deshielo en las zonas de montaña, que tarde o temprano terminan por sumarse a los caudales de los ríos.

Este ha sido un invierno muy lluvioso y templado, y una de sus principales consecuencias ha sido que buena parte de la región haya experimentado, entre otras cosas, cambios 
importantes en su paisaje. La proliferación de grandes charcas en las tierras de labor, la pronta aparición de musgos y plantas han traído en general un verdor prematuro. Además, los límpidos cielos castellanos de horizontes transparentes se han trocado por las atmósferas turbias y cubiertas más propias del norte.

Aunque en nuestro país normalmente las inundaciones más dramáticas por sus efectos son las que afectan a toda la fachada mediterránea por la intensidad con que se producen las precipitaciones, o bien las desarrolladas en Galicia por la persistencia de las mismas, las que se producen en Castilla y León aunque menos afamadas, destacan por su gran frecuencia y el elevado número de ríos a los que afectan. Son bastante diferentes, tanto por la época del año en que acontecen como por el tipo de precipitación que las caracteriza. Queda claro que los mismos efectos no siempre responden a las mismas causas.

No hay que olvidar que las inundaciones son de todos los riesgos climáticos los que ocasionan mayores daños en la región. Habrá que invertir más en ello y esperar que con prontitud se consigan los doce mil millones de pesetas necesarios para la instalación del SAIH en Castilla y León. Ello mejoraría sin duda la predicción. Pero también hay que abogar por cambios de mentalidad que permitan incorporar, de forma realista, los riesgos en el diseño de las normas urbanísticas y en la ordenación del territorio y, lo que es más importante, en su aplicación.

\section{Bibliografía}

BELTRÁN AUDERA, F. y PEJENAUTE GOÑI, J. (1995): «Las inundaciones en Navarra». Situaciones de riesgo climático en España, Instituto Pirenaico de Ecología. C.S.I.C. Jaca (Huesca). pp. 129-139.

CAMARASA BELMONTE, A.M. \& MATEU BELLÉS, J.F. (2000): «Las inundaciones en España en los últimos 20 años. Una perspectiva geográfica». Rev. Serie Geográfica. N ${ }^{\circ}$ 9, Madrid, $253 \mathrm{pp}$.

CAPEL MOLINA, J.J. (1983): Las inundaciones de agosto de 1983 en el País Vasco, Cantabria y Navarra Atlántica. La Crónica. Almería.

COMISIÓN NACIONAL DE PROTECCIÓN CIVIL Y MINISTERIO DE OBRAS PÚBLICAS Y TRANSPORTES (1988): Las inundaciones en la España peninsular. Madrid.

CORRAL CASTANEDO, A. (2000): Valladolid. Manifiesto o memoria de las desgracias ocurridas por la extraordinaria creciente del río Esgueva el 25 de febrero de 1788. Ed. facsímil. $220 \mathrm{pp}$.

DELEGACIÓN DE GOBIERNO EN CASTILLA Y LEÓN (1997): Plan provisional de emergencias por inundaciones en la provincia de Valladolid. Memoria. Valladolid. $93 \mathrm{pp}$.

FONT TULlOT, I. (1988): Historia del clima en España. Cambios climáticos y sus causas. Servicio de Publicaciones del INM. Madrid. 297 pp.

GARCÍA FERNÁNDEZ, J. (2000): Valladolid. De la ciudad a la aglomeración. Ed. Ariel. Valladolid. $350 \mathrm{pp}$.

GAZELLE, J. (1984): «La crue de décembre de 1981 dans la bassin de la Garonne». Revue Géographique des Pyrenées et du Sud-Ouest. Toulouse. Tome 55. pp. 5-28.

HERAS, R. (1983): Recursos hidráulicos, síntesis, metodología y normas. Ed. Col. Ingenieros de Caminos Canales y Puertos. Madrid. 361 pp.

INSTITUTO NACIONAL DE METEOROLOGÍA. Libro de efemérides meteorológicas. 
Ley 5/1999 de 8 de abril, de Urbanismo de Castilla y León. BOCyL. № 70, jueves 15 de abril 1999.

JUNTA DE CASTILLA Y LEÓN (1998): Directrices de ordenación territorial de Valladolid y entorno. Avance. $285 \mathrm{pp}$.

OLCINA CANTOS, J. (1994): Riesgos climáticos en la Península Ibérica. Ed. Penthalon. Madrid. 440 pp.

PERIÓDICOS: El Norte de Castilla, ABC Valladolid, El Día de Valladolid de los quince primeros días de marzo de 2001.

VERA REBOLLO, J.F. (1989): «Protección de cauces en el planeamiento urbanístico y la ordenación del territorio» en Avenidas fluviales e inundaciones en la cuenca del Mediterráneo. Caja de Ahorros del Mediterráneo e Instituto Universitario de Geografía. Alicante.

VV.AA. (2000): «Sur la séquence orageuse de novembre 1999» Geocarrefour. Revue de Géographie de Lyon. Vol. 75, n 3 . Monográfico 270 pp. 